\title{
Article \\ Performance Evaluation of Hybrid WOA-SVR and HHO-SVR Models with Various Kernels to Predict Factor of Safety for Circular Failure Slope
}

\author{
Wei Wei ${ }^{1,2}{ }^{2}$ Xibing Li ${ }^{1}$, Jingzhi Liu ${ }^{2}$, Yaodong Zhou ${ }^{2}$, Lu Li $^{2}$ and Jian Zhou ${ }^{1, *(D)}$ \\ 1 School of Resources and Safety Engineering, Central South University, Changsha 410083, Hunan, China; \\ weiw1987@outlook.com (W.W.); xbli@mail.csu.edu.cn (X.L.) \\ 2 Wanbao Mining Ltd., Xicheng District, Beijing 100053, China; liujingzhi@wbmining.com (J.L.); \\ zyd@wbmining.com (Y.Z.); 11 @@wbmining.com (L.L.) \\ * Correspondence: csujzhou@hotmail.com; Tel.: +86-181-7516-2802
}

check for updates

Citation: Wei, W.; Li, X.; Liu, J.; Zhou, Y.; Li, L.; Zhou, J. Performance Evaluation of Hybrid WOA-SVR and HHO-SVR Models with Various Kernels to Predict Factor of Safety for Circular Failure Slope. Appl. Sci. 2021, 11, 1922. https://doi.org/10.3390/ app11041922

Academic Editor:

Rodolfo Dufo-López

Received: 21 December 2020

Accepted: 10 February 2021

Published: 22 February 2021

Publisher's Note: MDPI stays neutral with regard to jurisdictional claims in published maps and institutional affiliations.

Copyright: (c) 2021 by the authors. Licensee MDPI, Basel, Switzerland. This article is an open access article distributed under the terms and conditions of the Creative Commons Attribution (CC BY) license (https:// creativecommons.org/licenses/by/ $4.0 /)$.

\begin{abstract}
To detect areas with the potential for landslides, slopes are routinely subjected to stability analyses. To this end, there is a need to adopt appropriate mitigation techniques. In general, the stability of slopes with circular failure mode is defined as the factor of safety (FOS). The literature includes a variety of numerical/analytical models proposed in different studies to compute the FOS values of slopes. However, the main challenge is to propose a model for solving a non-linear relationship between independent parameters (which have a great impact on slope stability) and FOS values of slopes. This creates a problem with a high level of complexity and with multiple variables. To resolve the problem, this study proposes a new hybrid intelligent model for FOS evaluation and analysis of slopes in two different phases: simulation and optimization. In the simulation phase, different support vector regression (SVR) kernels were built to predict FOS values. The results showed that the radius basis function (RBF) kernel produces more accurate performance prediction compared with the other applied kernels. The prediction accuracy of this kernel was obtained as coefficient of determination $=0.94$, which indicates a high prediction capacity during the simulation phase. Then, in the optimization phase, the proposed SVR model was optimized through the use of two well-known techniques, namely, the whale optimization algorithm (WOA) and Harris hawks optimization (HHO), and the optimum input parameters were obtained. The optimal results confirmed that both optimization techniques are able to achieve a high value for FOS of slopes; however, the HHO shows a more powerful process in FOS maximization compared with the WOA technique. In addition, the developed model was also successfully validated using new data with nine data samples.
\end{abstract}

Keywords: slope stability; factor of safety; support vector regression; whale optimization algorithm; Harris hawks optimization

\section{Introduction}

Landslides have been classified as one of the most hazardous natural events, causing damage to lots of public and private properties, and even human lives. Many countries spend a considerable amount of money annually to mitigate and control these events. To do this, one of the most straightforward and conventional steps is identifying potential landslide sections by conducting slope stability analyses. A number of parameters affect the stability of a slope; the most important ones are the geometrical shape of the slope, its gravity, the shear strength of geomaterial, and the water quantity in the soil. Generally, the above-noted parameters are represented by five different factors: the slope height, the porepressure ratio, the slope angle, the soil unit weight, and the soil shear strength parameters (i.e., cohesion and angle of internal friction) [1]. These parameters bring lots of uncertainties to the problem, which makes slope stability analysis a statistically indeterminate problem 
with a high non-linearity. Different researchers have proposed different assumptions with the aim of simplifying this problem, which has resulted in the development of several methods for slope stability analysis [2,3].

Typically, the stability of a slope is expressed by the term 'factor of safety' (FOS). If the FOS value is greater than one, the slope is thought to be safe. To compute the FOS value, several methods have been suggested in different studies. Two conventional types applied for this purpose are numerical methods (such as finite element method, finite difference method, and discrete element method) and limit equilibrium methods (LEMs) [4,5]; both have certain advantages as well as drawbacks. Finite element methods are used to analyze slope stability for two-dimensional and three-dimensional simulation. However, each method has its advantages and disadvantages. Two-dimensional methods are usually conservative and can differ by up to 30\% from three-dimensional results. This creates unsafe designs for FOS projects. On the other hand, 3D models have a higher execution time, which also reduces their use [6,7]. In general, these traditionally used methods are complex and iterative and cause an overloaded computation system [8]. Such faults have obliged researchers working in this field to make attempts to propose alternative approaches to slope stability computation.

In recent years, a number of studies have used soft computing techniques (e.g., vector machine algorithm, neural networks, etc.) to solve such highly complicated, multivariate, non-linear problems. In various fields of science and engineering, intelligent methods have proven to be highly efficient in function approximation [9-32]. Different studies have developed various models based on artificial neural networks (ANNs), support vector regression (SVR), and random forest techniques to solve such complex problems [33-39]. Several researchers have employed these methods to work on the slope stability problem $[1,3,8,40,41]$. ANN and SVR essentially predict the relationship between the input(s) and output for a certain set of data. These methods include various strengths and weaknesses, which can be improved with optimization algorithms such as genetic algorithm (GA), particle swarm optimization (PSO), differential evolution (DE), and ant colonization optimization (ACO). Optimization algorithms are used to optimize various problems. Complex problems can be simulated well using a combination of different models. Table 1 summarizes some of the past proposed works in the area of slope stability using soft computing techniques.

Table 1. Summary of some studies that applied soft computing techniques to evaluate the factor of safety (FOS).

\begin{tabular}{|c|c|c|}
\hline Author (Reference) & Soft Computing Technique & Aim \\
\hline Verma et al. [42] & ANN & $\begin{array}{l}\text { Provide a hybrid ANN-FEM model for slope stability } \\
\text { analysis and FOS }\end{array}$ \\
\hline Rukhaiyar et al. [43] & PSO-ANN & $\begin{array}{c}\text { Development of a hybrid model for FOS evaluation and } \\
\text { comparison with numerical methods }\end{array}$ \\
\hline Chakraborty et al. [44] & ANN & $\begin{array}{l}\text { Applying multiple linear regression and ANN models } \\
\text { for } 200 \text { cases and comparison with analytical methods }\end{array}$ \\
\hline Koopialipoor et al. [41] & $\begin{array}{l}\text { Imperialist competitive algorithm } \\
\text { (ICA)-ANN, GA-ANN, PSO-ANN and } \\
\text { artificial bee colony (ABC)-ANN }\end{array}$ & $\begin{array}{c}\text { Development of various ANN models using } \\
4 \text { optimization algorithms and evaluation of FOS with } \\
\text { different conditions }\end{array}$ \\
\hline Samui et al. [45] & SVR & $\begin{array}{c}\text { FOS forecasting using SVR method and testing of } \\
\text { real cases }\end{array}$ \\
\hline Abdalla et al. [46] & ANN & $\begin{array}{c}\text { Prediction of minimum FOS against slope failure in } \\
\text { clayey soils using ANN }\end{array}$ \\
\hline Khandelwal et al. [47] & ANN & $\begin{array}{c}\text { Calculate the factor of safety of dump slope of a coal } \\
\text { mine using developed ANNs }\end{array}$ \\
\hline
\end{tabular}

In this research, a simulation was implemented to evaluate FOS using an SVR model. In this simulation, different models were designed based on four kernels. Finally, the model with the lowest error and with high accuracy was optimized by two new algorithms, namely, the whale optimization algorithm (WOA) and Harris hawks optimization (HHO). This problem was optimized using a combination of SVR and HHO-WOA models. The 
results show that a new methodology can be proposed for FOS parameter analysis. This article has the following sections: The second section discusses the analysis methods for FOS. Then, a review of the data conditions is performed, and simulation and optimization models are implemented. Finally, the article continues with discussion and conclusions about the applications of this research.

\section{Methodology}

\subsection{Support Vector Regression (SVR)}

SVR, pioneered by Cortes and Vapnik [48], is an algorithm that works based on machine learning. This algorithm is extensively used in numerous fields such as blasting, tunneling, landslides, and rockburst [49-55]. It is broadly used to solve many regressionand classification-related problems. SVR generally uses a mapping of data with an $f(x)$ function for the aim of transforming a low-dimensional non-linear dataset into a highdimensional linear problem in feature space. The SVR for regression can be defined as follows.

Assume a training dataset $\mathrm{T}=\left\{\left(x_{1}, y_{1}\right),\left(x_{2}, y_{2}\right), \ldots,\left(x_{k}, y_{k}\right)\right\}$, where $x_{i}$ and $y_{i}$ stand for the input and output, respectively, then $x_{i} \in R^{n}$ and then $y_{i} \in R$, and $k$ signifies the training observations. The SVM model for the regression problem can be calculated as follows [48]:

$$
f(x)=a \cdot \delta(x)+b
$$

where $a . \delta(x)$ stands for the kernel function. Table 2 presents a list of some types of kernel functions for regression. These functions can be effectively used to transform a dataset from a low to a higher dimension for SVR.

Table 2. Types of kernel used in this research.

\begin{tabular}{ccc}
\hline Kernel & Function & Parameter \\
\hline Linear & $X, Y$ & - \\
Polynomial & $(\mathrm{gX} . \mathrm{Y}+\mathrm{c}) \mathrm{d}$ & $\mathrm{g}, \mathrm{c}, \mathrm{d}$ \\
Radius basis function $(\mathrm{RBF})$ & $\exp \left(-\mathrm{g}|X-\mathrm{X}|^{2}\right)$ & $\mathrm{g}$ \\
Sigmoid & $\tanh (\mathrm{gX} . \mathrm{Y}+\mathrm{c})$ & $\mathrm{g}, \mathrm{c}$ \\
\hline
\end{tabular}

Then, the Lagrangian can be solved as follows:

$$
\max \sum_{i=1}^{k} y_{i}\left(\hat{\varepsilon}_{i}-\varepsilon_{i}\right)-\eta\left(\hat{\varepsilon}_{i}-\varepsilon_{i}\right)-\frac{1}{2} \sum_{i=1}^{k} \sum_{j=1}^{k}\left(\hat{\varepsilon}_{i}-\varepsilon_{i}\right)\left(\hat{\varepsilon}_{j}-\varepsilon_{j}\right) \delta\left(x_{i}, x_{j}\right)
$$

where

$$
\left\{\begin{array}{c}
\sum_{i=1}^{k}\left(\hat{\varepsilon}_{i}-\varepsilon_{i}\right)=0 \\
0 \leq \varepsilon_{i}, \hat{\varepsilon}_{i} \leq C, i=1,2, \ldots k
\end{array}\right.
$$

where $C$ represents the penalty factor (cost) of a kernel function. For the dataset to be mapped, Equation (2) needs to meet the conditions of Karush-Kuhn-Tucker [56] as:

$$
\left\{\begin{array}{c}
\varepsilon_{i}\left(f\left(x_{i}\right)-y_{i}-\eta-\omega_{i}\right)=0 \\
\hat{\varepsilon}_{i}\left(y_{i}-f\left(x_{i}\right)-\varepsilon-\hat{\omega}_{i}\right)=0 \\
\varepsilon_{i} \hat{\varepsilon}_{i}=0 ; \omega_{i} \hat{\omega}_{i}=0 \\
\left(C-\varepsilon_{i}\right) \omega_{i}=0 ;\left(C-\hat{\varepsilon}_{i}\right) \hat{\omega}_{i}=0
\end{array}\right.
$$

The SVM for regression can be finally solved as follows:

$$
f(x)=\sum_{i=1}^{k}\left(\hat{\varepsilon}_{i}-\varepsilon_{i}\right) \cdot \delta\left(x_{i}, x_{j}\right)+b
$$




$$
b=y_{i}+\eta-\sum_{i=1}^{k}\left(\hat{\varepsilon}_{i}-\varepsilon_{i}\right) \cdot \delta\left(x_{i}, x_{j}\right)+b
$$

\subsection{Whale Optimization Algorithm (WOA)}

This algorithm, which was originally developed on the basis of the natural behaviors of humpback whales $[20,24,57,58]$, is an alternative swarm algorithm. WOA, like the other swarm optimization algorithms, starts its operation with an initial population. Then, it computes an objective function for each member of the population (solution). To end with, the optimum solution is selected on the basis of the humpback whales' strategies, e.g., encircling the prey and creating a bubble-net. To encircle, WOA updates the current solution; therefore:

$$
\operatorname{SWi}(t+1)=\operatorname{SWbest}(t)-G D
$$

where

$$
\left\{\begin{array}{l}
G=2 c r_{2}-c \\
D=|S W b e s t(t)-S W i(t)|, E=2 r_{1}
\end{array}\right.
$$

where $D$ stands for the distance between solution $S W i(t)$ at iteration $(t)$ and the best solution SWbest $(\mathrm{t}), r_{1}$ and $r_{2}$ represent random coefficients in the interval $[0,1]$, which is the element-wise multiplication operation, and $c$ signifies a coefficient of iteration varying in the intervals $[0,2]$ and is computed as follows:

$$
C=c-t \frac{c}{\text { MaxIterw }}
$$

In the bubble-net making phase, WOA updates the solution with the use of encircling or spiral methods [57]. First, the shrinking circling method is implemented with the strategy of coefficient iteration c expressed in Equation (9). Otherwise, the spiral technique is adopted for the aim of updating the solution in WOA. The algorithm makes a simulation of the helix-shaped movement. This movement (defined by Equation (10)) is indeed a unique action taken by whales around the best solution (SWbest) when preying:

$$
\operatorname{SWi}(t+1)=D e^{s k} \cos (2 \pi k)+\operatorname{SWbest}(t)
$$

where

$$
\dot{D}=\mid \text { SWbest }(t)-S W i(t) \mid
$$

where $s$ represents the logarithmic spiral shape, and $k$ stands for a random variable in the interval $[1,1]$. In addition, as suggested by Mirjalili and Lewis [57], the WOA solutions can be updated through switching between spiral-shaped and shrinking; consequently:

$$
S W i(t+1)=\left\{\begin{array}{cc}
S W b e s t(t)-G D & \text { if } r_{3} \geq 0.5 \\
D e^{s k} \cos (2 \pi k)+S W b e s t(t) & \text { if } r_{3} \leq 0.5
\end{array}\right.
$$

where $r_{3}$ denotes the probability of swathing in which $r_{3} \in[0,1]$. In nature, whales often adopt another strategy when preying (to choose the optimal solution), i.e., the random search method. In this method, a random position is chosen rather than the optimal solution; therefore:

$$
S W i(t+1)=S W_{r}(t)-G D
$$

where

$$
D=|E \delta S W r(t)-S W i(t)|
$$

Remember that, according to Mirjalili and Lewis [57], updating the WOA solutions is dependent upon different parameters such as $c, G, E$, and $r_{3}$. The WOA optimization process terminates once the stopping criterion (i.e., minimum error or maximum iterations reached) is met and the best solution is obtained. Figure 1 displays the developed code of WOA. 


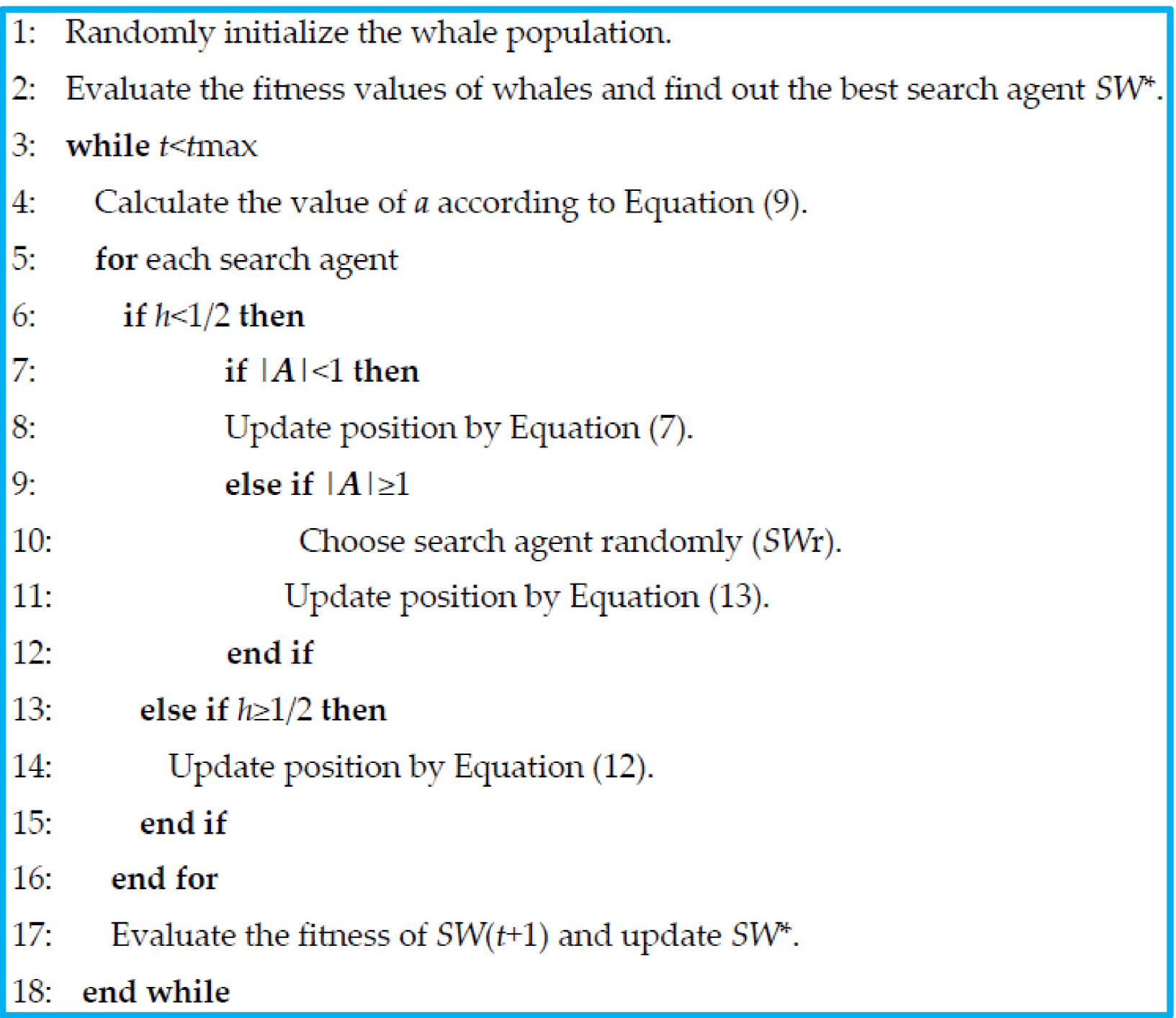

Figure 1. The developed code of whale optimization algorithm (WOA).

\subsection{Harris Hawks Optimization (HHO)}

The co-operative hunting behavior of Harris's hawks has been taken into consideration for the purpose of representing different issues for which optimum solutions are required [59] in the Harris hawks optimization (HHO) algorithm [60] proposed by Heidari et al. (2019). In this optimization process, four actions are represented: tracing, encircling, approaching, and attacking.

As depicted by Figure 2, HHO comprises three phases: Exploration, Exploitation, and a Transition Phase in between. During the first phase, the hawk searches and finds the exact location of the prey and its position Xrabit. The hawks assigns a random relationship to the prey Xrand and then defines their own position in relation to the prey position, implementing an iterative process:

$X($ iter +1$)=X_{\text {rand }}($ iter $)-r_{1} X_{\text {rand }}($ iter $)-2 r_{2} X($ iter $)$ if $q \geq 0.5 X_{\text {rabit }}($ iter $)-X_{m}($ iter $)-r_{3}\left(L B+r_{4}(U B-L B)\right)$ if $q<0.5$

where $\mathrm{X} m$ stands for the average position, and ri denotes a position based on $i$, a random number that varies from $I=(1,2,3,4, \ldots q)$. 


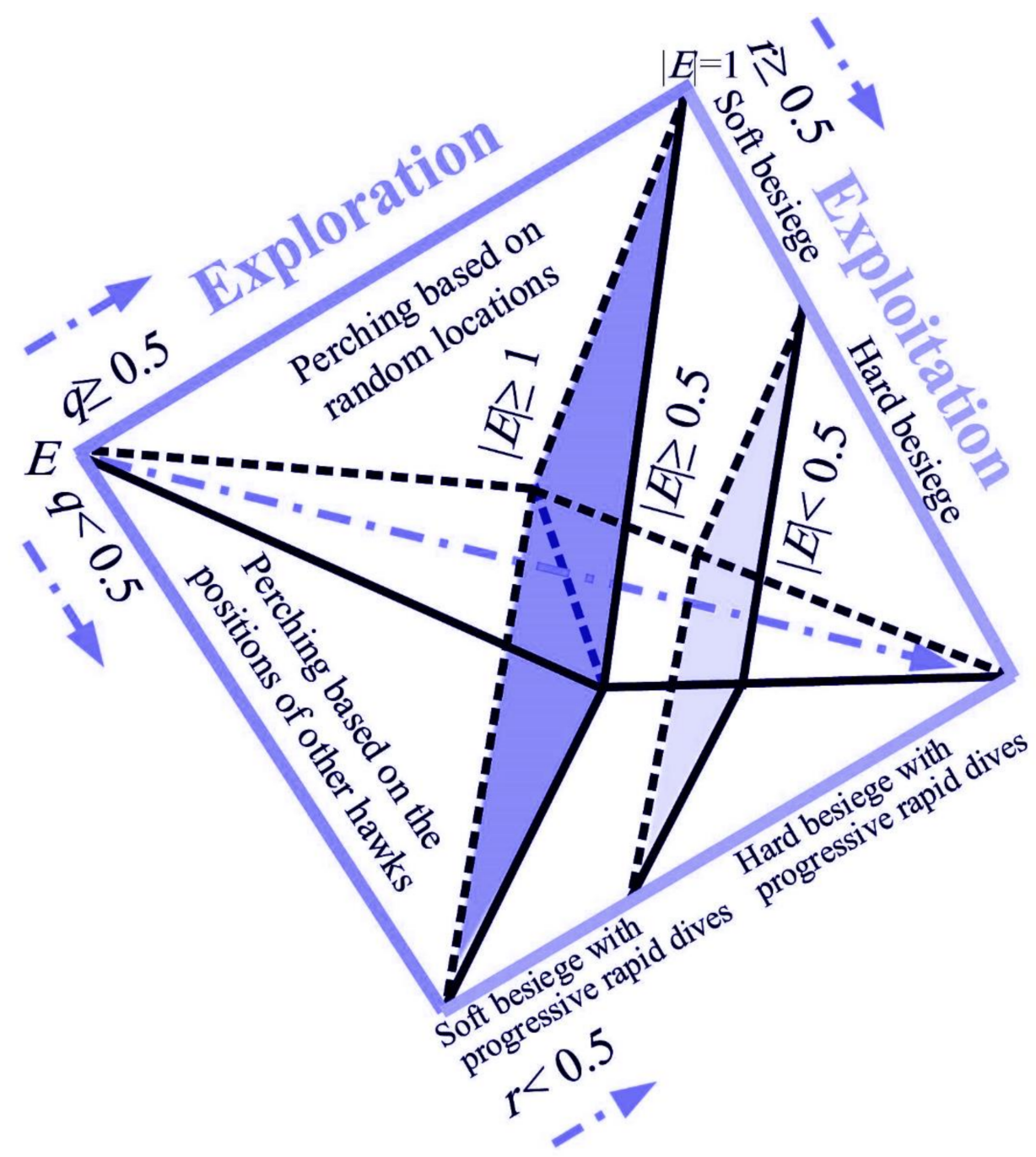

Figure 2. The main stages of Harris hawks optimization (HHO).

The term $\mathrm{m}$ is given by the following equation:

$$
X m(\text { iter })=\frac{1}{N} \sum_{i=1}^{N} X_{i}(\text { iter })
$$

where $N$ signifies the size of the hawk and $\mathrm{Xi}$ stands for the location. $E_{h}$, the escaping energy of the hunt, is given by the following relationship:

$$
E_{h}=2 E_{0}\left(1-\frac{i \text { ter }}{T}\right)
$$

where $T$ represents the maximum size of the repetitions, and $E_{0}$ signifies the initial energy. Remember that $E_{0} \in(-1,1)$ and the decision about starting the exploration or exploitation phase depends upon the $|E|$ value. For example, in the exploitation phase, the $|E|$ value indeed denotes the type of attack arranged for capturing the rabbit. In the case $|E| \geq 0.5$, the catch is considered easy, while if $|E|<0.5$, it will be difficult $[61,62]$.

\subsection{Evaluation}

In statistical science, both the reliability and performance of models are required to be assessed in a quantitative way with the use of statistical indicators. For this purpose, in the current study, two statistical criteria were adopted, i.e., correlation coefficient $\left(R^{2}\right)$ 
and RMSE. $R^{2}$ shows the difference between the estimated and actual FOS values, whereas RMSE represents the model's error rate. They are computed as follows [20,50,63-70]:

$$
\begin{gathered}
R M S E=\sqrt{\frac{1}{n} \sum_{i=1}^{n}\left(y_{f r, i}-\hat{y}_{f r, i}\right)^{2}} \\
R^{2}=1-\frac{\sum_{i=1}^{n}\left(y_{f r, i}-\hat{y}_{f r, i}\right)^{2}}{\sum_{i=1}^{n}\left(y_{f r, i}-\bar{y}_{f r, i}\right)^{2}}
\end{gathered}
$$

where $n$ stands for the number of FOS cases, $y_{f r, i}$ and $\hat{y}_{f r, i}$ represent the measured and the estimated FOS values, respectively, and $\bar{y}_{f r, i}$. signifies the mean of the FOS in reality.

\section{Results and Discussion}

\subsection{Data Preparation}

The current research was carried out assuming the circular critical failure of slopes. A database comprising 80 slope cases (formerly analyzed considering circular failure mode) was extracted from the existing literature $[1,43,71-76]$. Table 3 provides the datasets used in this study. Six key parameters were extracted, i.e., the unit weight of slope material $(\gamma)$, cohesion $(c)$ and angle of internal friction $(\phi)$, average angle of slope $(\beta)$, shear strength parameter, pore water pressure coefficient $(r u)$, and the slope height $(H)$. Table 4 summarizes the slope stability database regarding the minimum (Min), average (Ave), maximum, standard deviation, and median values. This condition causes the slope stability analysis to be a problem of high complexity.

\begin{tabular}{|c|c|c|c|c|c|c|}
\hline $\begin{array}{l}\text { Density } \\
\left(\mathrm{kn} / \mathrm{m}^{3}\right)\end{array}$ & C (kpa) & $\phi$ (degree) & $\beta$ (degree) & $\mathrm{H}(\mathrm{m})$ & ru & FOS \\
\hline 18.68 & 26.34 & 15 & 35 & 8.23 & 0 & 1.11 \\
\hline 18.84 & 14.36 & 25 & 20 & 30.5 & 0 & 1.875 \\
\hline 18.84 & 57.46 & 20 & 20 & 30.5 & 0 & 2.045 \\
\hline 28.44 & 29.42 & 35 & 35 & 100 & 0 & 1.78 \\
\hline 28.44 & 39.23 & 38 & 35 & 100 & 0 & 1.99 \\
\hline 20.6 & 16.28 & 26.5 & 30 & 40 & 0 & 1.25 \\
\hline 14 & 11.97 & 26 & 30 & 88 & 0 & 1.02 \\
\hline 25 & 120 & 45 & 53 & 120 & 0 & 1.3 \\
\hline 26 & 150.05 & 45 & 50 & 200 & 0 & 1.2 \\
\hline 22.4 & 10 & 35 & 30 & 10 & 0 & 2 \\
\hline 21.4 & 10 & 30.34 & 30 & 20 & 0 & 1.7 \\
\hline 22 & 20 & 36 & 45 & 50 & 0 & 1.02 \\
\hline 16 & 70 & 20 & 40 & 115 & 0 & 1.11 \\
\hline 20.41 & 24.9 & 13 & 22 & 10.67 & 0.35 & 1.4 \\
\hline 19.63 & 11.97 & 20 & 22 & 12.19 & 0.405 & 1.35 \\
\hline 21.82 & 8.62 & 32 & 28 & 12.8 & 0.49 & 1.03 \\
\hline 18.84 & 15.32 & 30 & 25 & 10.67 & 0.38 & 1.63 \\
\hline 19.06 & 11.71 & 28 & 35 & 21 & 0.11 & 1.09 \\
\hline 18.84 & 14.36 & 25 & 20 & 30.5 & 0.45 & 1.11 \\
\hline 21.51 & 6.94 & 30 & 31 & 76.81 & 0.38 & 1.01 \\
\hline 18 & 24 & 30.15 & 45 & 20 & 0.12 & 1.12 \\
\hline 22.4 & 100 & 45 & 45 & 15 & 0.25 & 1.8 \\
\hline 22.4 & 10 & 35 & 45 & 10 & 0.4 & 0.9 \\
\hline 20 & 20 & 36 & 45 & 50 & 0.25 & 0.96 \\
\hline 20 & 20 & 36 & 45 & 50 & 0.5 & 0.83 \\
\hline 21 & 20 & 40 & 40 & 12 & 0 & 1.84 \\
\hline 21 & 45 & 25 & 49 & 12 & 0.3 & 1.53 \\
\hline 21 & 30 & 35 & 40 & 12 & 0.4 & 1.49 \\
\hline 21 & 35 & 28 & 40 & 12 & 0.5 & 1.43 \\
\hline
\end{tabular}

Table 3. The complete dataset used to develop models. 
Table 3. Cont.

\begin{tabular}{|c|c|c|c|c|c|c|}
\hline $\begin{array}{l}\text { Density } \\
\left(\mathrm{kn} / \mathrm{m}^{3}\right)\end{array}$ & C (kpa) & $\phi$ (degree) & $\beta$ (degree) & $\mathbf{H}(\mathrm{m})$ & ru & FOS \\
\hline 20 & 40 & 30 & 30 & 15 & 0.3 & 1.84 \\
\hline 18 & 45 & 25 & 25 & 14 & 0.3 & 2.09 \\
\hline 19 & 30 & 35 & 35 & 11 & 0.2 & 2 \\
\hline 20 & 40 & 40 & 40 & 10 & 0.2 & 2.31 \\
\hline 18.85 & 24.8 & 21.3 & 29.2 & 37 & 0.5 & 1.07 \\
\hline 18.85 & 10.34 & 21.3 & 34 & 37 & 0.3 & 1.29 \\
\hline 18.8 & 30 & 10 & 25 & 50 & 0.1 & 1.4 \\
\hline 18.8 & 25 & 10 & 25 & 50 & 0.2 & 1.18 \\
\hline 18.8 & 20 & 10 & 25 & 50 & 0.3 & 0.97 \\
\hline 19.1 & 10 & 10 & 25 & 50 & 0.4 & 0.65 \\
\hline 18.8 & 30 & 20 & 30 & 50 & 0.1 & 1.46 \\
\hline 18.8 & 25 & 20 & 30 & 50 & 0.2 & 1.21 \\
\hline 18.8 & 20 & 20 & 30 & 50 & 0.3 & 1 \\
\hline 19.1 & 10 & 20 & 30 & 50 & 0.4 & 0.65 \\
\hline 22 & 20 & 22 & 20 & 180 & 0 & 1.12 \\
\hline 22 & 20 & 22 & 20 & 180 & 0.1 & 0.99 \\
\hline 25 & 55 & 36 & 45 & 239 & 0.25 & 1.71 \\
\hline 25 & 63 & 32 & 44.5 & 239 & 0.25 & 1.49 \\
\hline 25 & 63 & 32 & 46 & 300 & 0.25 & 1.45 \\
\hline 25 & 48 & 40 & 45 & 330 & 0.25 & 1.62 \\
\hline 31.3 & 68.6 & 37 & 47.5 & 262.5 & 0.25 & 1.2 \\
\hline 31.3 & 68.6 & 37 & 47 & 270 & 0.25 & 1.2 \\
\hline 31.3 & 58.8 & 35.5 & 47.5 & 438.5 & 0.25 & 1.2 \\
\hline 31.3 & 58.8 & 35.5 & 47.5 & 502.7 & 0.25 & 1.2 \\
\hline 31.3 & 68 & 37 & 47 & 360.5 & 0.25 & 1.2 \\
\hline 27.3 & 14 & 31 & 41 & 110 & 0.25 & 1.249 \\
\hline 27 & 40 & 35 & 43 & 420 & 0.25 & 1.15 \\
\hline 27 & 50 & 40 & 42 & 407 & 0.25 & 1.44 \\
\hline 27 & 35 & 35 & 42 & 359 & 0.25 & 1.27 \\
\hline 27 & 32 & 33 & 42.4 & 289 & 0.25 & 1.3 \\
\hline 27 & 32 & 33 & 42.6 & 301 & 0.25 & 1.16 \\
\hline 25 & 46 & 35 & 46 & 393 & 0.25 & 1.31 \\
\hline 25 & 48 & 40 & 49 & 330 & 0.25 & 1.49 \\
\hline 31.3 & 68.6 & 37 & 47 & 305 & 0.25 & 1.2 \\
\hline 25 & 55 & 36 & 45.5 & 299 & 0.25 & 1.52 \\
\hline 31.3 & 68 & 37 & 47 & 213 & 0.25 & 1.2 \\
\hline 22 & 29 & 15 & 18 & 400 & 0 & 1.04 \\
\hline 23 & 24 & 19.8 & 23 & 380 & 0 & 1.15 \\
\hline 22 & 40 & 30 & 30 & 196 & 0 & 1.11 \\
\hline 22.54 & 29.4 & 20 & 24 & 210 & 0 & 1.06 \\
\hline 22 & 21 & 23 & 30 & 257 & 0 & 1.1 \\
\hline 23.5 & 10 & 27 & 26 & 190 & 0 & 1.02 \\
\hline 22.5 & 18 & 20 & 20 & 290 & 0 & 1.05 \\
\hline 22.5 & 20 & 16 & 25 & 220 & 0 & 1.36 \\
\hline 21 & 20 & 24 & 21 & 565 & 0 & 1.26 \\
\hline 26.49 & 150 & 33 & 45 & 73 & 0.15 & 1.23 \\
\hline 26.7 & 150 & 33 & 50 & 130 & 0.25 & 1.8 \\
\hline 26.89 & 150 & 33 & 52 & 120 & 0.25 & 1.8 \\
\hline 26.43 & 50 & 26.6 & 40 & 92.2 & 0.15 & 1.25 \\
\hline 26.7 & 50 & 26.6 & 50 & 170 & 0.25 & 1.25 \\
\hline 26.8 & 60 & 28.8 & 59 & 108 & 0.25 & 1.25 \\
\hline
\end{tabular}


Table 4. The main statistical information of the dataset.

\begin{tabular}{ccccccc}
\hline Parameter & Type & Min & Max & Average & $\begin{array}{c}\text { Standard } \\
\text { Deviation }\end{array}$ & Median \\
\hline$\gamma$ & input & 14 & 31.3 & 22.9337 & 4.0706 & 22 \\
$c$ & input & 6.94 & 150.05 & 40.4358 & 33.1699 & 30 \\
$\phi$ & input & 10 & 45 & 28.8924 & 8.6297 & 30.075 \\
$\beta$ & input & 18 & 59 & 36.2587 & 10.3505 & 37.5 \\
$r u$ & input & 0 & 0.5 & 0.1936 & 0.1515 & 0.25 \\
$H$ & input & 8.23 & 565 & 149.1659 & 142.6898 & 96.1 \\
FOS & target & 2.31 & 0.65 & 1.3305 & 0.3369 & 1.2495 \\
\hline
\end{tabular}

\subsection{Study Steps}

One of the main objectives of this research is FOS optimization based on intelligent methods and optimization algorithms. In this methodology, different SVR models are implemented to obtain the best model for FOS simulation. These models are analyzed with different statistical criteria in order to identify the model that has more flexibility than other models by proper comparison. In the next step, the two optimization algorithms $\mathrm{HHO}$ and WOA are connected to the superior SVR model. The purpose of this work is to optimize the identified parameters to maximize the FOS value. This was done by coding in the MATLAB environment. For each analysis, a series of different designs of intelligent models and optimization algorithms are performed to achieve the best conditions. The steps outlined in the flowchart are shown in Figure 3.

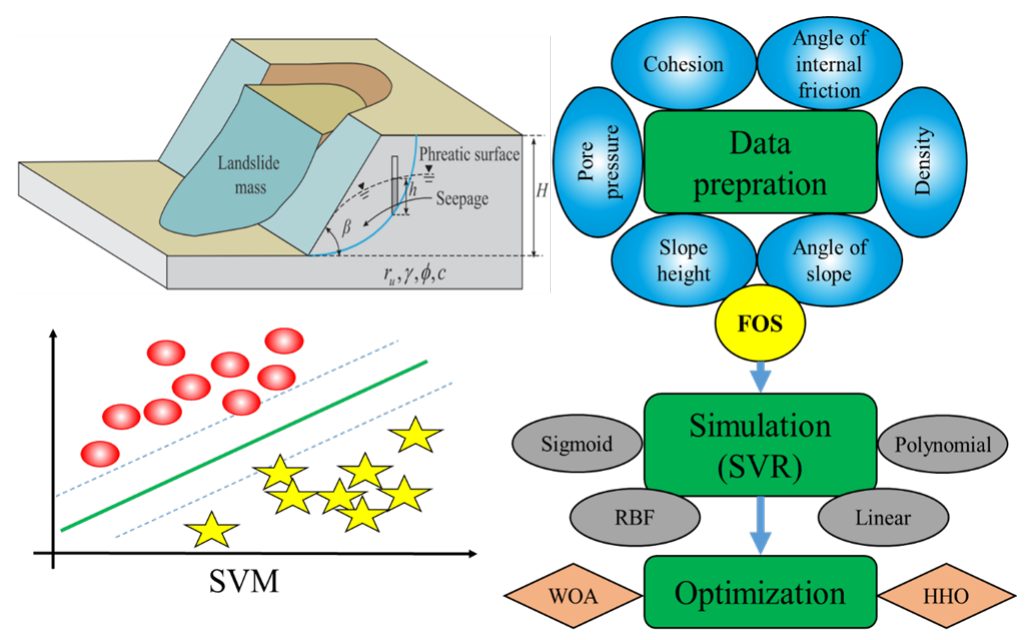

Figure 3. The main flowchart of the current research.

\subsection{Simulation}

In this section, different SVR models were used to simulate and evaluate FOS. Based on this step, optimization models are developed. The data used in this study include 80 data samples. Due to different conditions, 6 input parameters of these models were used without change. For more accurate evaluation, the data were divided into two parts: training and testing. Different and optimal conditions were designed to determine the superior models. Finally, the best model that could provide suitable conditions for different data for FOS prediction was determined. Each parameter has a specific effect on the data and results of the models. Visualization of a correlation matrix of slope data is shown in Figure 4. In Figures 5-10, the effect of each parameter on the output is investigated. Using these figures, the input data can be examined more accurately. These data can provide specific conditions and significant changes in model results. However, important ranges can also be identified through various studies. With the help of these cases, proper accuracy in FOS simulation and optimization can be achieved. This research has considered these cases in the simulations. 


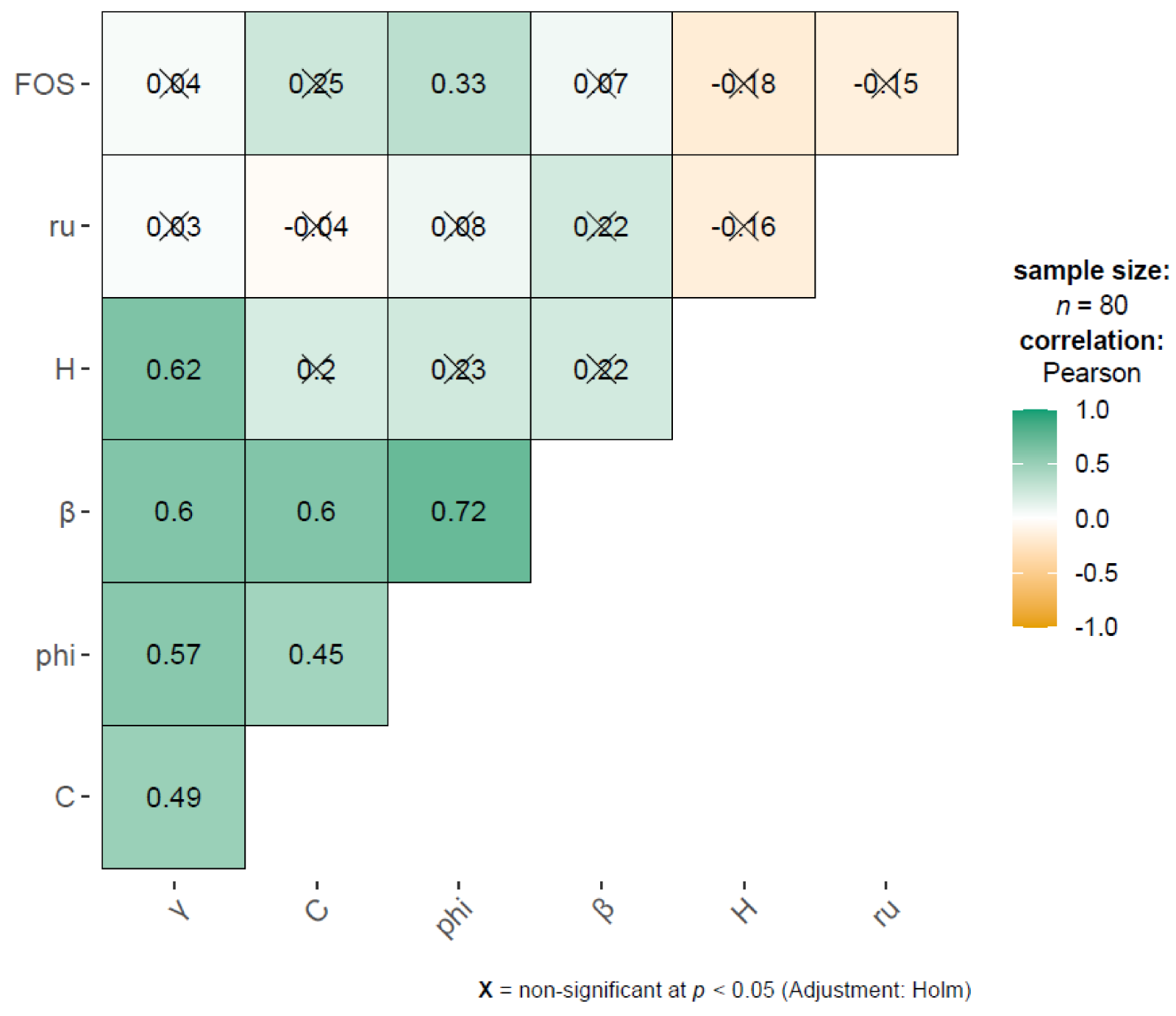

Figure 4. Correlation matrix (aka correlalogram) plot of slope data.

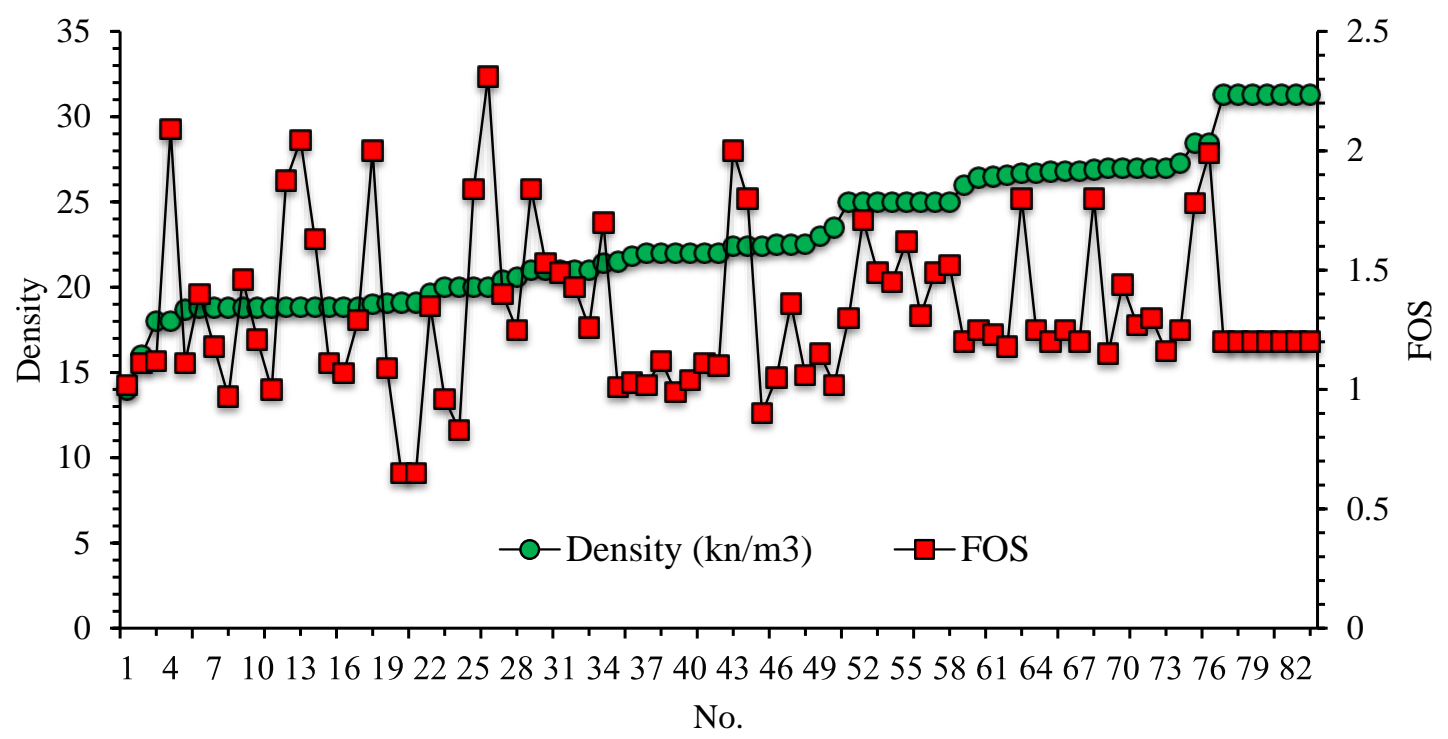

Figure 5. Density-FOS changes. 


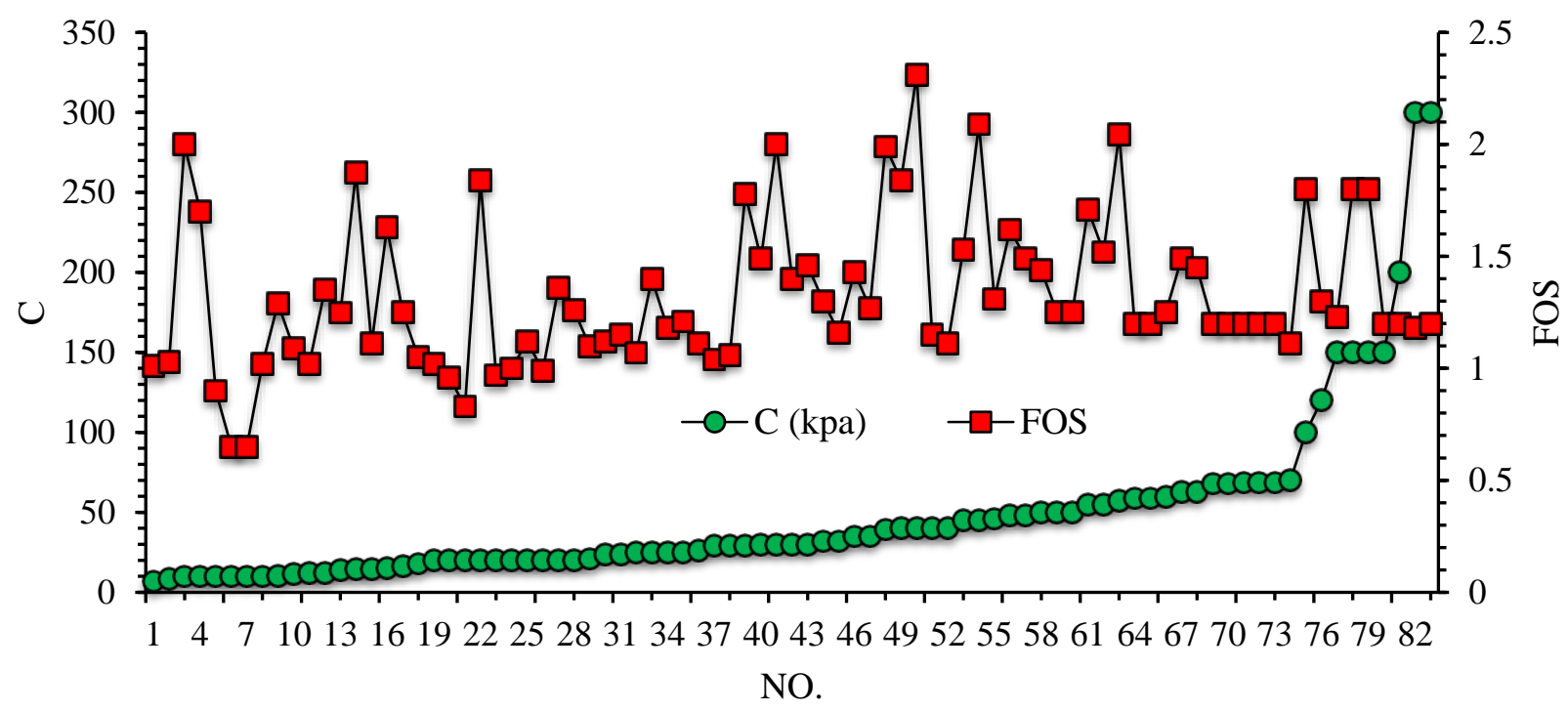

Figure 6. C-FOS changes.

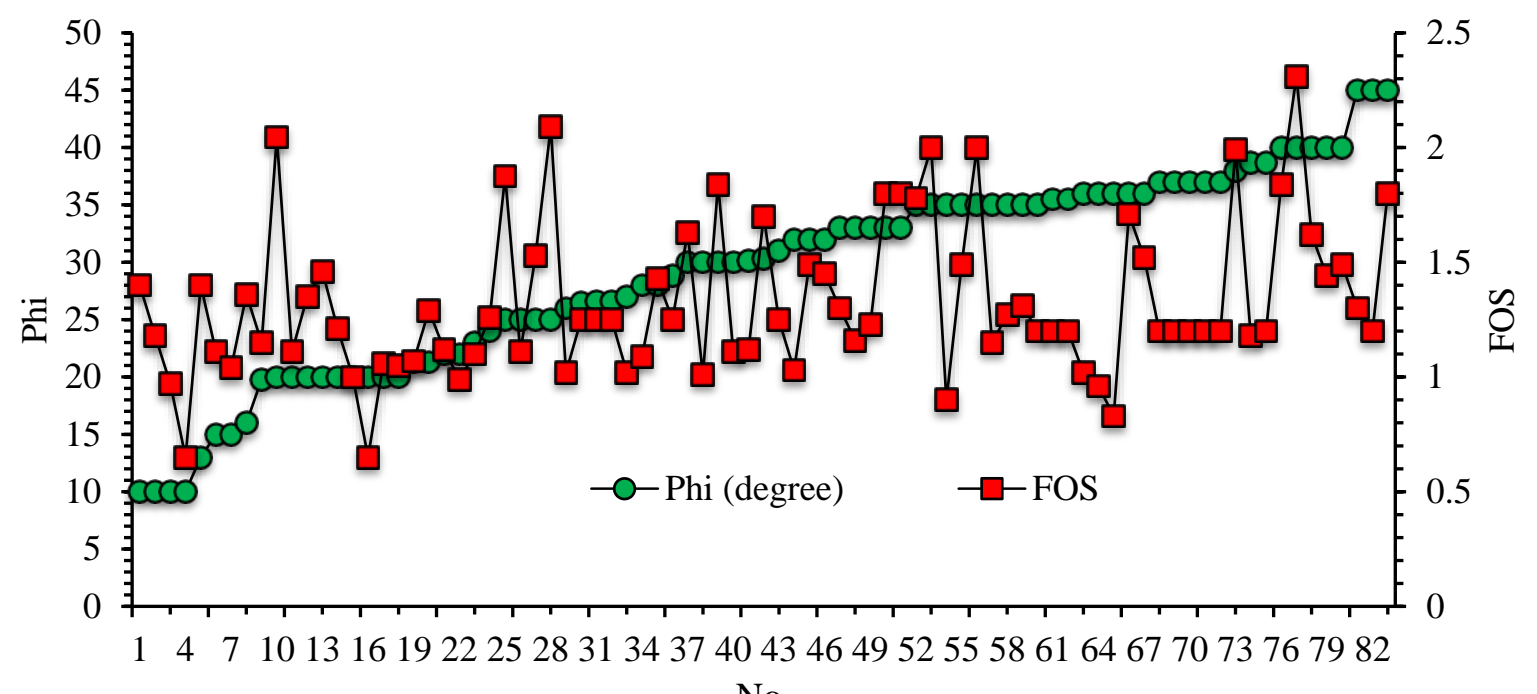

Figure 7. $\phi$-FOS changes.

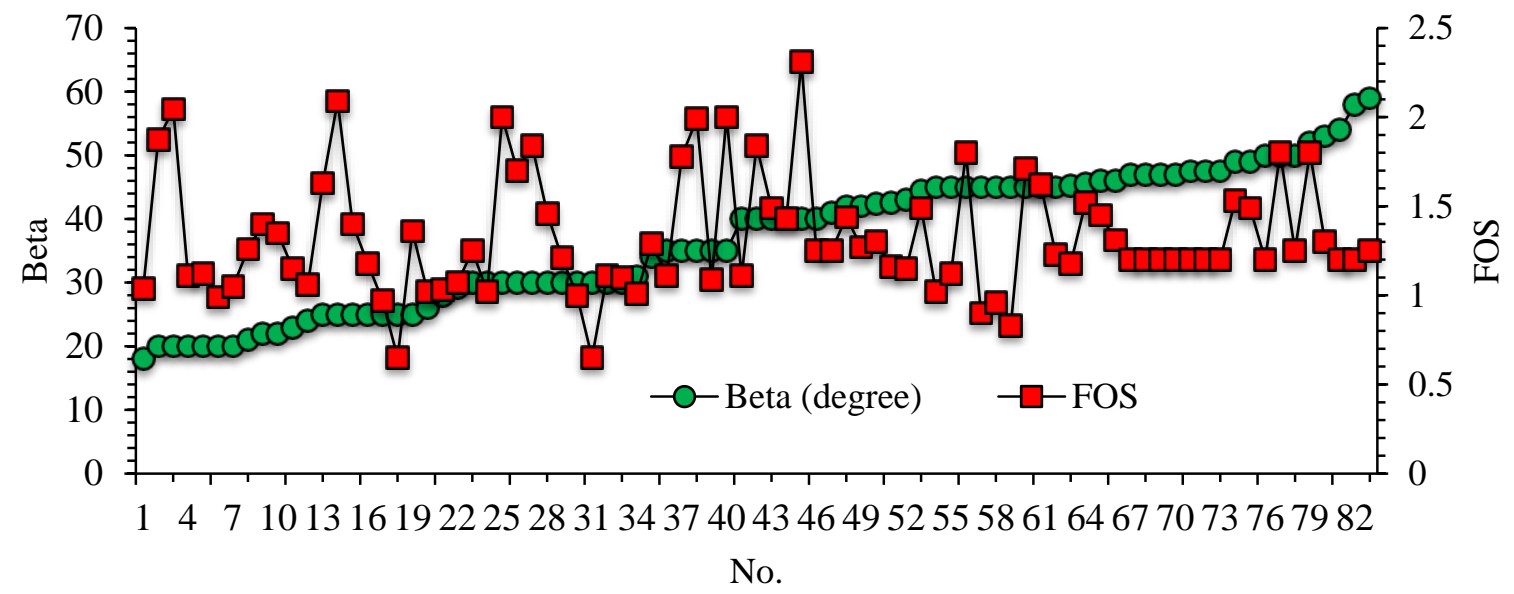

Figure 8. $\beta$-FOS changes. 


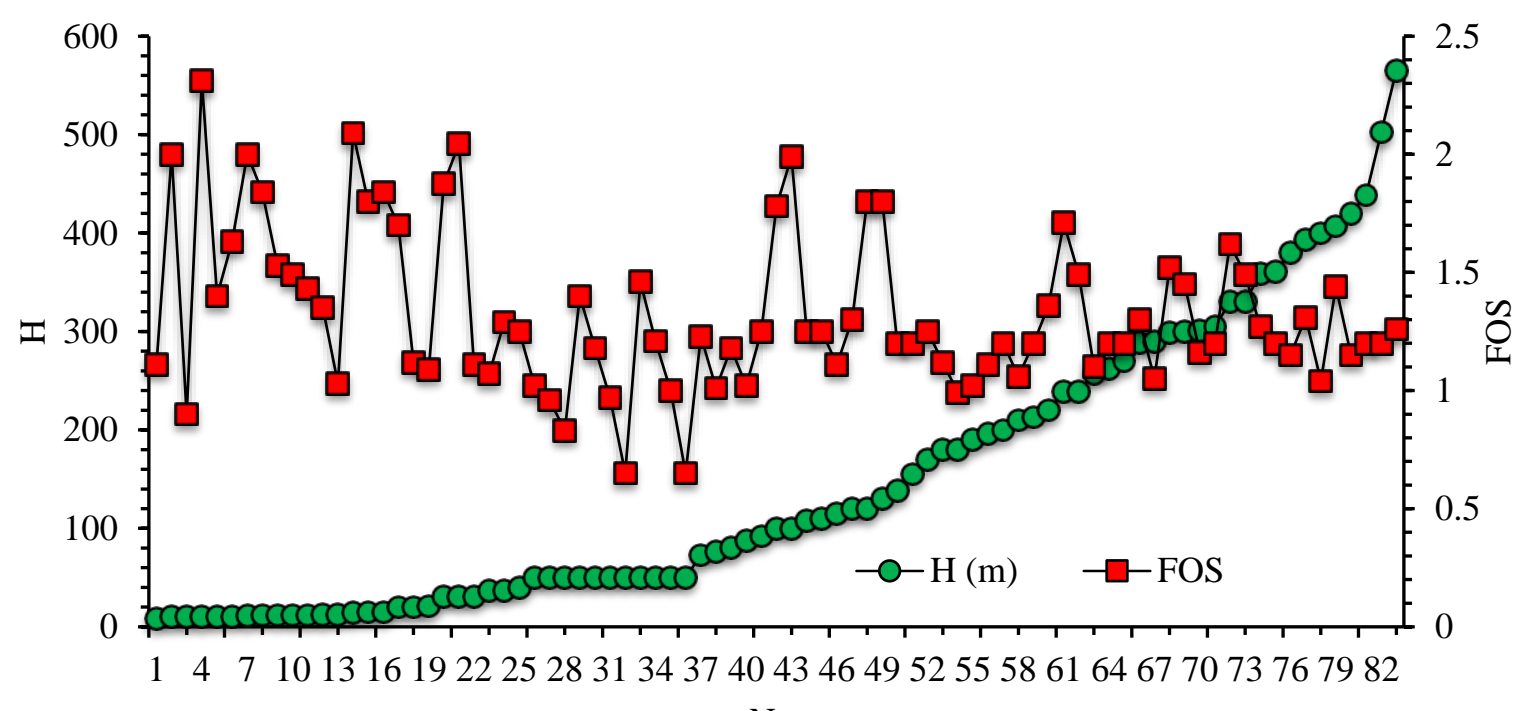

No.

Figure 9. H-FOS changes.

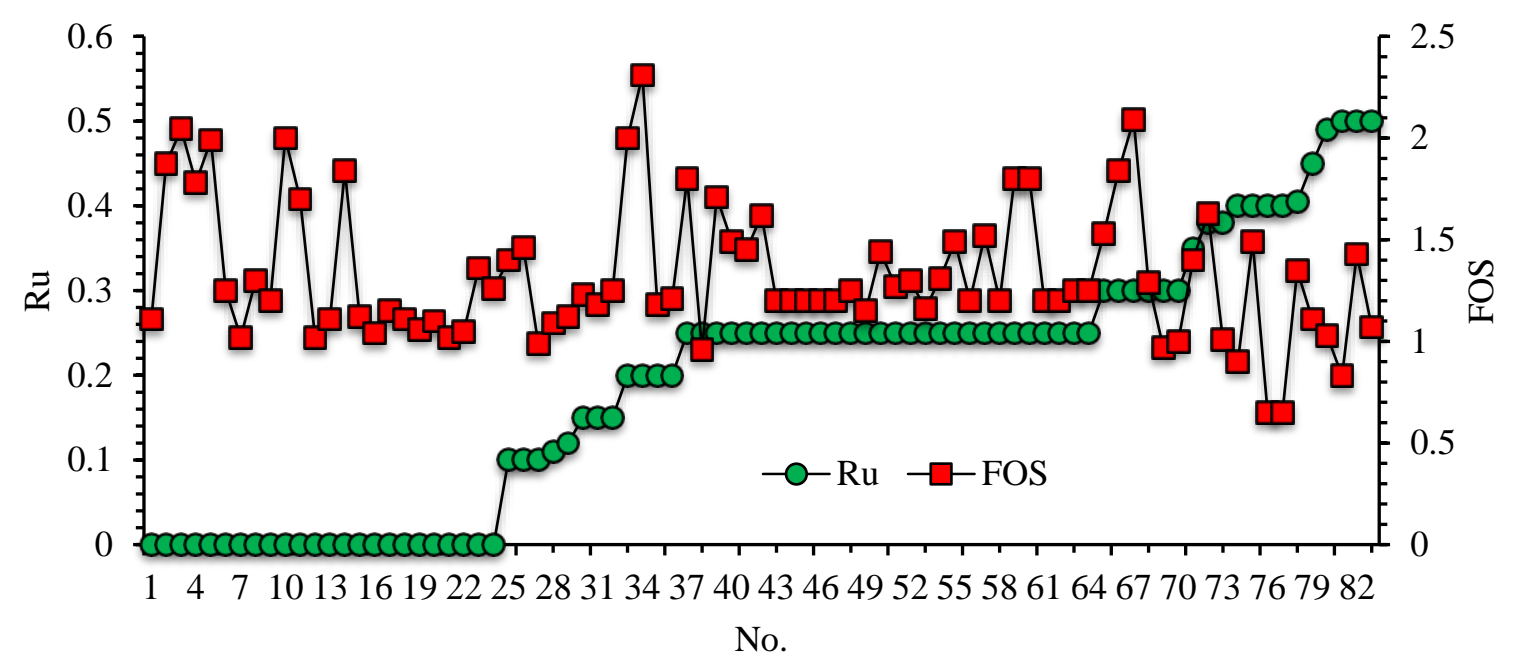

Figure 10. Ru-FOS changes.

Table 5 provides the simulation results for four different SVR models. To achieve the best conditions of each model, parametric analysis was performed to determine the optimal parameters of each model. As can be seen, both polynomial and RBF models provide better conditions for FOS simulation. The RBF model with an accuracy of $R^{2}=0.947$ shows that a more appropriate assessment can be made than other models to simulate the problem in this research. Figure 11 indicates the simulation results for four models. As can be seen, the data are simulated with higher accuracy by the RBF model. The model developed in this step is evaluated using optimization algorithms to determine the optimal conditions of the parameters used for FOS. Figure 12 shows the error changes of the models. Using this figure, the range of changes from prediction values to actual values can be obtained. As can be seen, the RBF model provides limited error variations. This indicates that for different samples, the predicted data are in the appropriate range and a good ability to perform them is observed. 
Table 5. Results of various models for simulation of FOS.

\begin{tabular}{ccccc}
\hline SVR Model & $\begin{array}{c}\text { Optimal } \\
\text { Parameters }\end{array}$ & $\boldsymbol{R}^{\mathbf{2}}$ & $\begin{array}{c}\text { Result } \\
\text { RMSE }\end{array}$ & MAE \\
\hline Linear & - & 0.267 & 0.284 & 0.236 \\
Polynomial & $\mathrm{g}=0.3, \mathrm{c}=0.09$, & 0.868 & 0.120 & 0.086 \\
RBF & $\mathrm{d}=3$ & 0.947 & 0.076 & 0.046 \\
Sigmoid & $\mathrm{g}=0.42$ & 0.214 & 0.294 & 0.243 \\
\hline
\end{tabular}

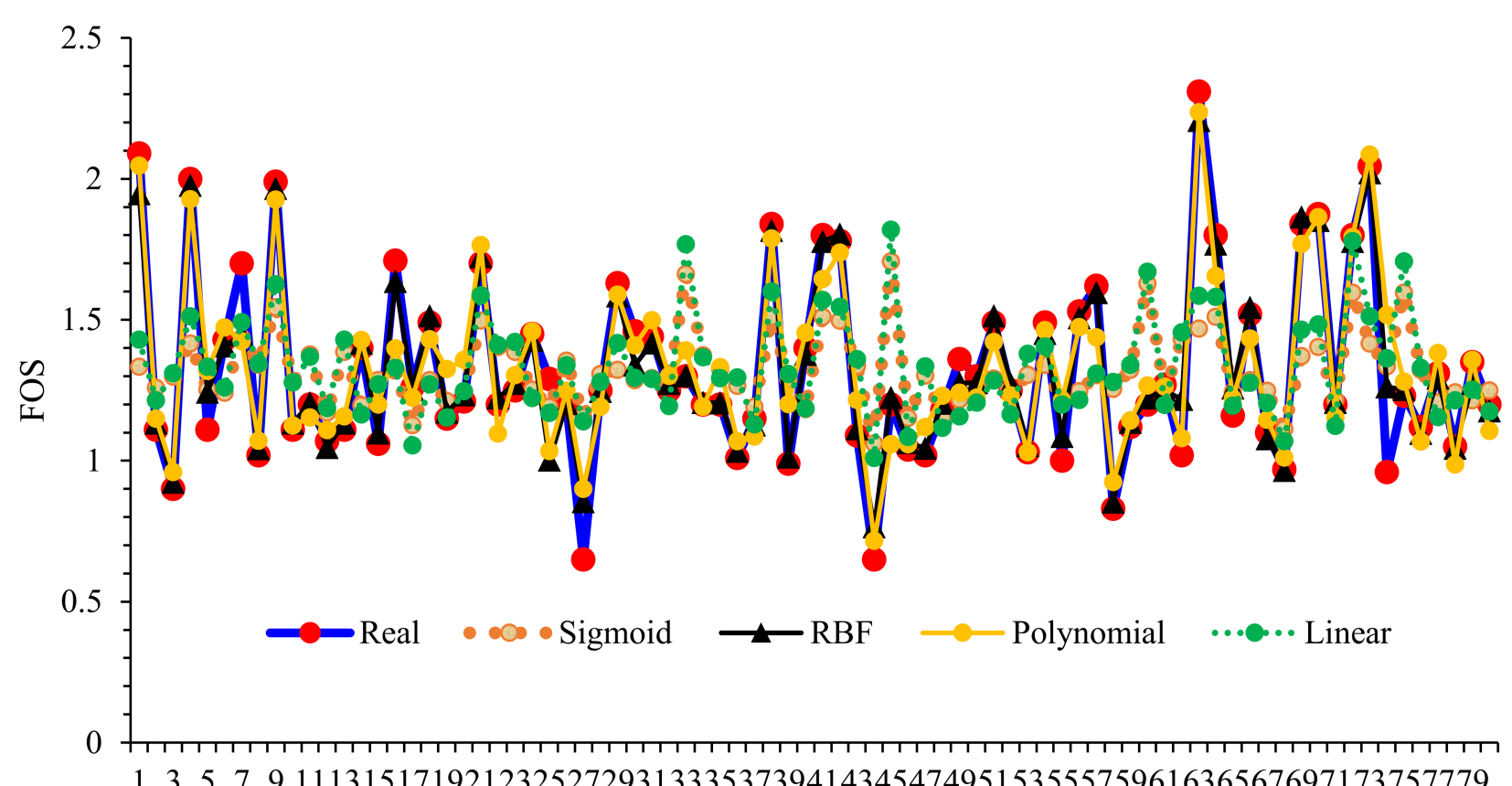

No.

Figure 11. Simulation results for FOS based on various support vector regression (SVR) models.

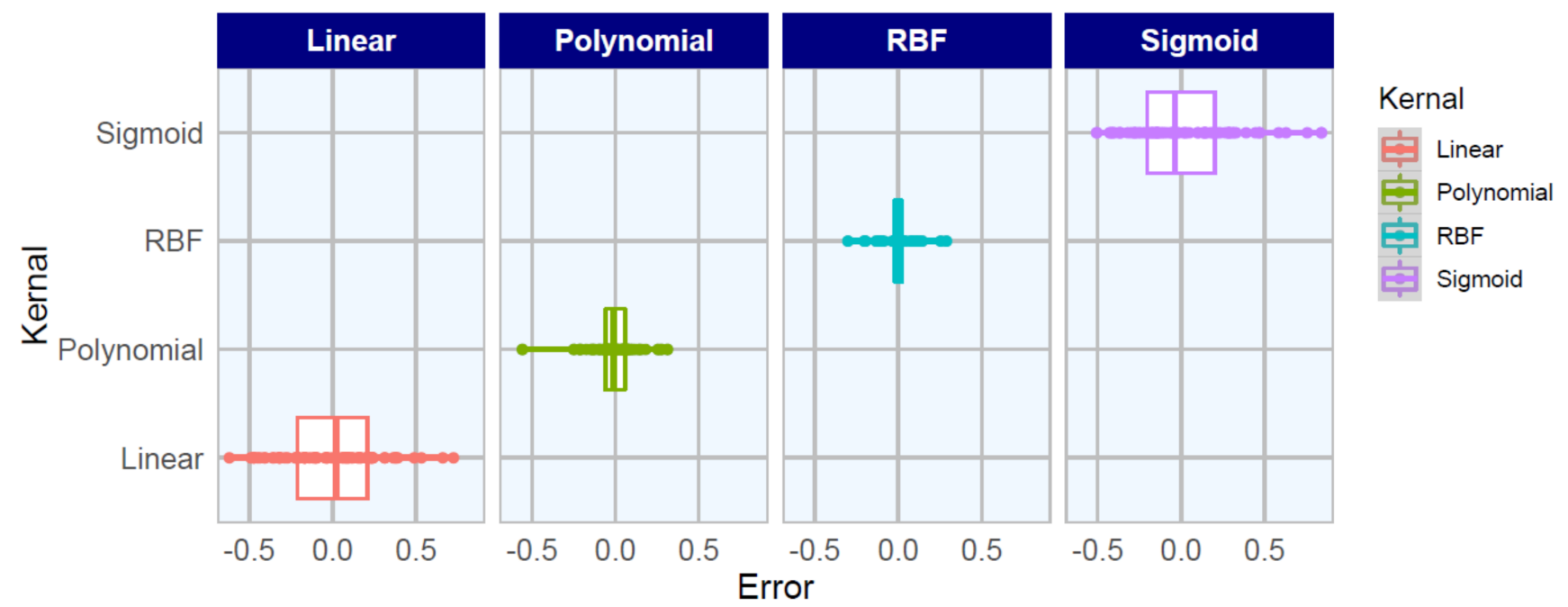

Figure 12. The error changes of the developed models for simulation of FOS. 


\subsection{Model Validation}

This section presents our model validation using new data with nine data samples from the L \& K mine of Monyova copper mines, as presented in Table 6. These new cases were used to validate the developed RBF-SVR model in this study. Figure 13 displays FOS results related to new data and the developed model. As can be seen, the RBF-SVR model has generally provided an acceptable performance against new data that have been practically recorded. According to Figure 13, five cases are very close to each other, i.e., $(1.11,1.17),(1.08,1.16),(2.15,2.06),(1.26,1.19)$, and $(1.24,1.18)$. The other four cases have a bigger difference between new data and the developed model. It can be concluded that the performance of the developed model in this research offers a positive response for optimization analyses that require a high-precision model. The developed model is able to obtain the least error for optimal parameters.

Table 6. Additional data for the purpose of model verification.

\begin{tabular}{|c|c|c|c|c|c|c|}
\hline $\begin{array}{l}\text { Density } \\
\left(\mathrm{kn} / \mathrm{m}^{3}\right)\end{array}$ & C (kpa) & $\phi$ (degree) & $\beta$ (degree) & $\mathbf{H}(\mathrm{m})$ & ru & FOS \\
\hline 25.578 & 14.62 & 42.16 & 46 & 495 & 0 & 1.16 \\
\hline 22.834 & 8.35 & 40.21 & 44 & 420 & 0 & 1.18 \\
\hline 22.148 & 3.2 & 36.88 & 40 & 40 & 0 & 2.59 \\
\hline 23.814 & 6.96 & 37.44 & 40 & 80 & 0 & 2.19 \\
\hline 25.088 & 8.26 & 37.94 & 42 & 100 & 0 & 1.86 \\
\hline 25.872 & 22.67 & 41.21 & 50 & 307 & 0 & 1.19 \\
\hline 23.422 & 2.48 & 35.11 & 40 & 80 & 0 & 2.06 \\
\hline 25.284 & 5.99 & 38.22 & 46 & 260 & 0 & 1.18 \\
\hline 25.382 & 6.52 & 40.47 & 46 & 260 & 0 & 1.17 \\
\hline
\end{tabular}

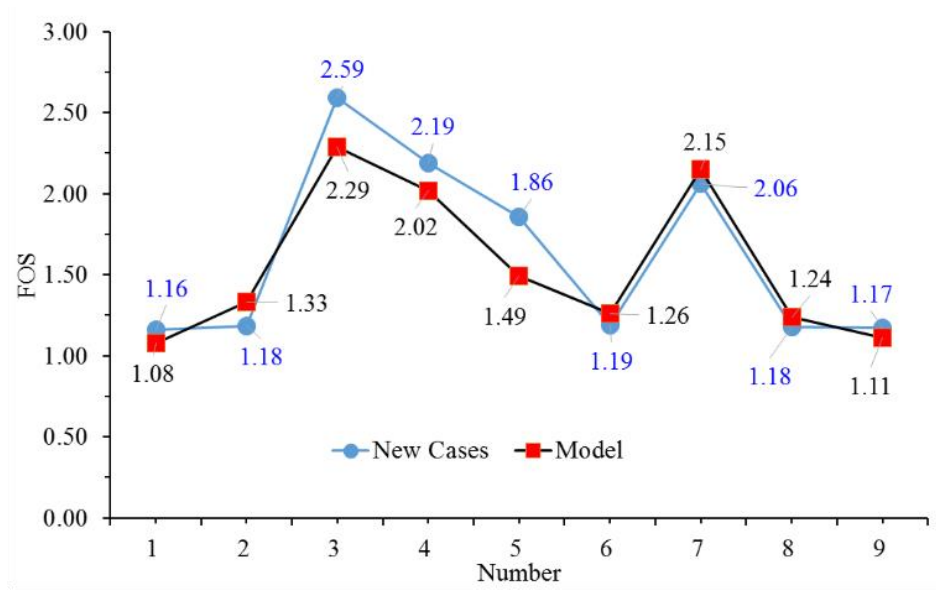

(a)

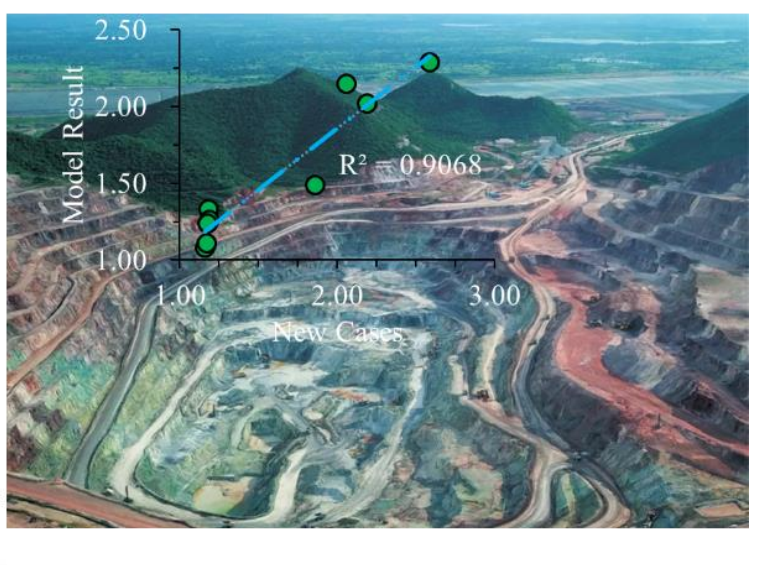

(b)

Figure 13. FOS results of new cases obtained by the developed radius basis function (RBF)-SVR model: (a) predicted v.s. measured, and (b) a view of L \& K mine of Monyova copper mines.

\subsection{Optimization}

In this section, optimization algorithms connect to predictive models, and search for optimal conditions for FOS. Since each optimization model requires a function in order to obtain the optimal conditions, the regression model of the previous stage that was developed is used here. Due to this fact, four models were developed in the previous step for FOS simulation. Among the developed models, two models had better conditions for evaluating this issue. The RBF model can act as a better option than the polynomial model 
because it was more accurate and could offer greater flexibility for evaluation. Therefore, in this part, the RBF model is used as the base model.

The RBF model is connected to two optimization algorithms, WOA and HHO, so that different parameters can be optimized. The two WOA and HHO models were implemented in MATLAB software. To examine their performance in solving various problems, four sample problems were used to find optimal locations. Figure 14 shows the comparison results between these models. As can be seen, the models have the ability to find the optimal locations. The goal is to find the optimal and sensitive conditions for FOS. Since each optimization algorithm has its own conditions, its parameters must also be determined for the optimal state. Therefore, numerical analysis was performed on the two optimization algorithms WOA and $\mathrm{HHO}$ to find their optimal coefficients. After determining the optimal coefficients, the algorithms use the basic RBF model to obtain the optimal conditions. Table 7 presents the optimal parameters determined based on the two WOA and HHO algorithms. As can be seen, the optimization algorithms can each offer different optimal conditions that can be used depending on the different conditions. The solution of the algorithms shows that each goes to the optimal state and ultimately leads to the desired results. In general, it can be inferred from the results that using optimization methodology, more efficient designs can be done for engineering and sensitive projects.

Table 7. Optimal parameters of FOS based on WOA and HHO.

\begin{tabular}{|c|c|c|}
\hline \multicolumn{2}{|c|}{ Optimal Values } & \multirow[t]{2}{*}{ Parameters } \\
\hline HHO & WOA & \\
\hline 28.0186 & 30.548 & $\gamma$ \\
\hline 159.1915 & 199.118 & $c$ \\
\hline 27.209 & 39.8714 & $\phi$ \\
\hline 44.5905 & 29.8562 & $\beta$ \\
\hline 0.3128 & 0.1915 & ru \\
\hline 563.3418 & 397.9759 & $H$ \\
\hline 2.4411 & 2.4301 & FOS \\
\hline
\end{tabular}



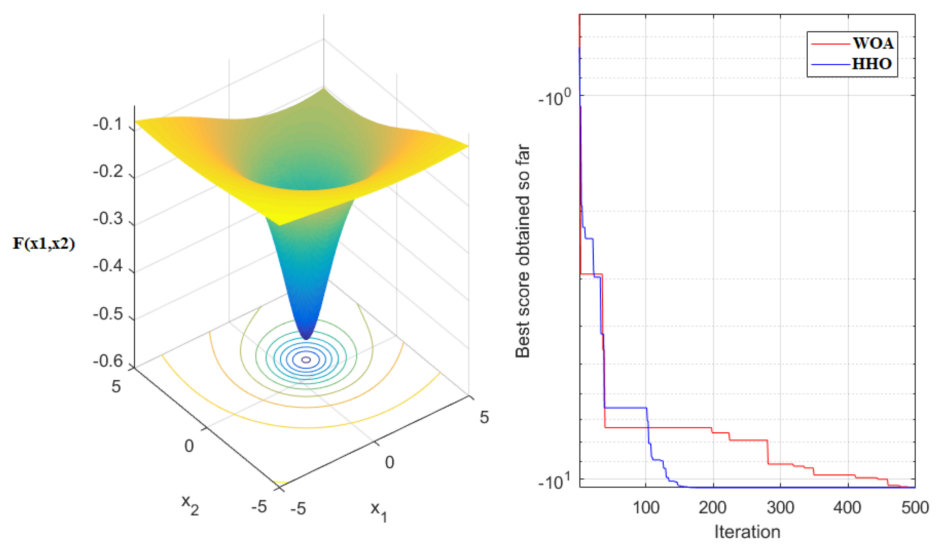

(a) Sample problem 1
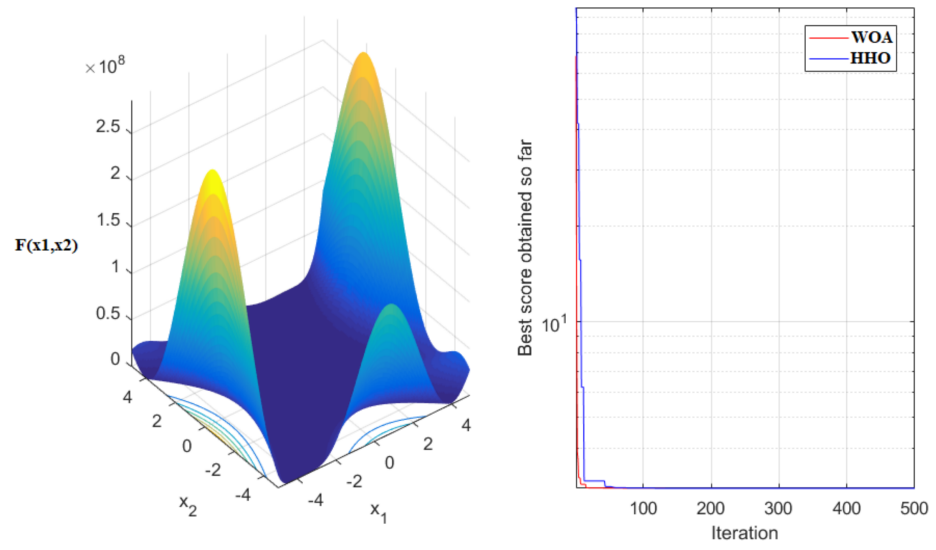

(b) Sample problem 2
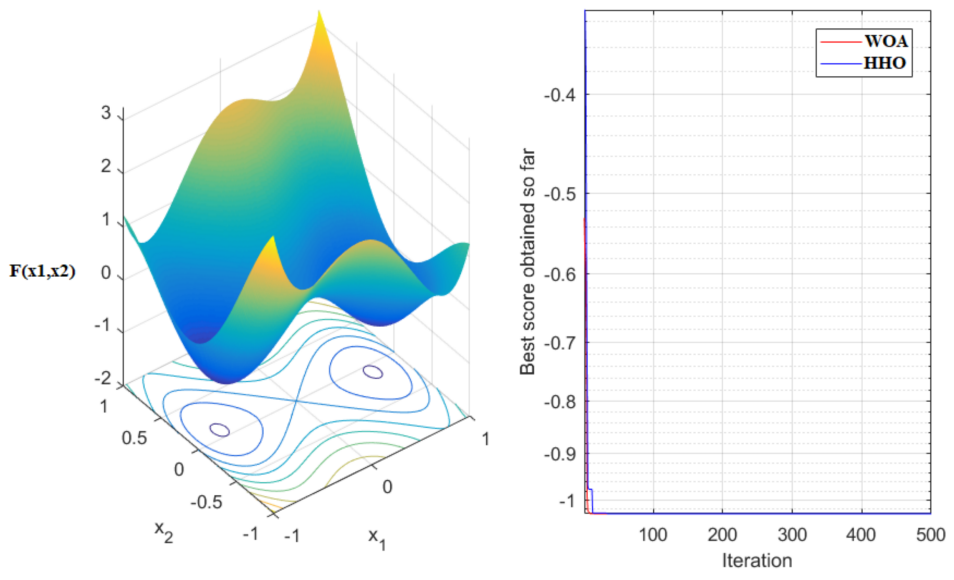

(c) Sample problem 3

Figure 14. Cont. 

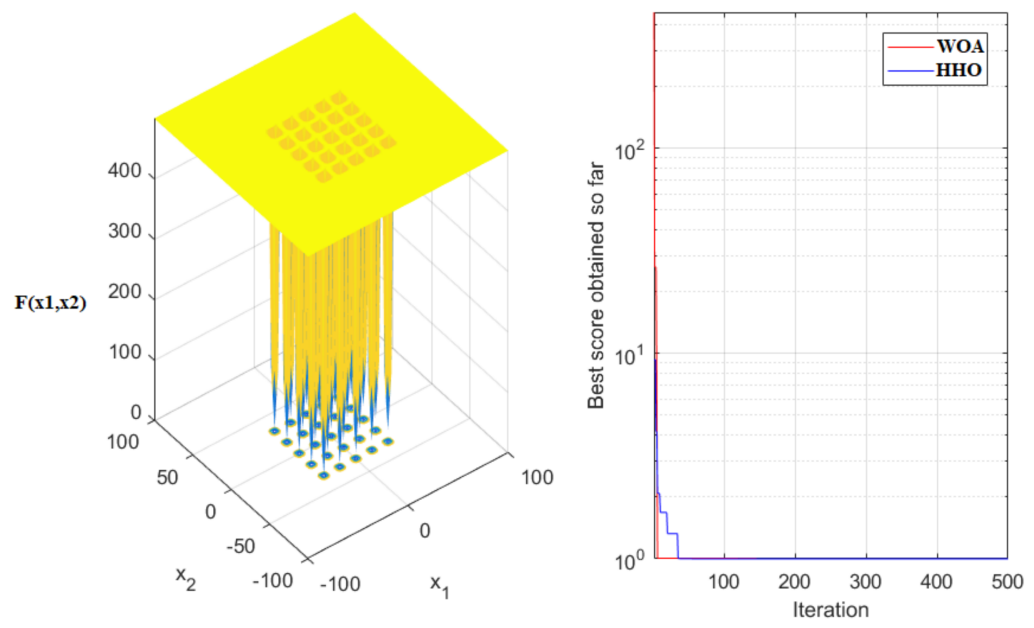

(d) Sample problem 4

Figure 14. Evaluation of optimization models (WOA and HHO) to solve various problems.

\section{Discussion}

The method used in this research is a new way to analyze slope data. The simulations performed in this project allow a good estimate to be obtained based on the six input data (the unit weight of slope material $(\gamma)$, cohesion $(c)$ and angle of internal friction $(\phi)$, average angle of slope $(\beta)$, shear strength parameter, pore water pressure coefficient $(r u)$, and the slope height $(H)$ ) for the FOS parameter. The accuracy of the evaluation models was about $R^{2}=0.947$, which indicates a high accuracy for the data used. This accuracy also shows that it provides different predicted results with less error intervals. All of these conditions help us to achieve an optimal pattern with less error. Optimization algorithms create different solutions according to the data conditions and the relationship between different parameters. The two optimization algorithms connected to the superior RBF model determined the optimal conditions by identifying the various parameters that were introduced as inputs. Figure 15 displays the different FOS values and the optimal states by the two WOA and HHO algorithms. As can be seen, it can be concluded from this figure that with optimization, more suitable conditions can be found. In addition, by combining simulation and optimization models, more accurate accuracy can be achieved for project design. This article presents a new idea based on artificial intelligence and optimization methods, which can be extended to different applications.

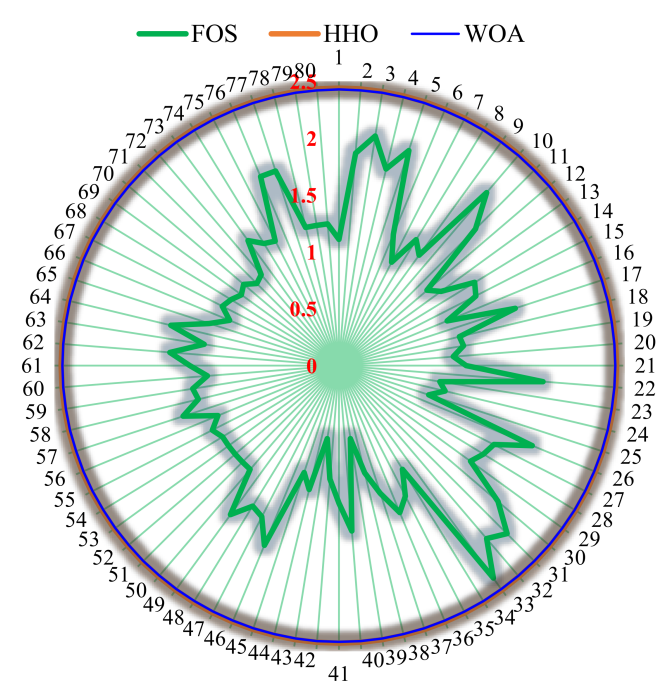

Figure 15. Comparison between different FOS and output of optimization models. 


\section{Conclusions}

This research has used computational intelligence to investigate the FOS in measurement cases under different conditions. For model design and simulation, this study was implemented based on six parameters, namely, the unit weight of slope material $(\gamma)$, cohesion $(c)$ and angle of internal friction $(\phi)$, average angle of slope $(\beta)$, shear strength parameter, pore water pressure coefficient $(r u)$, and the slope height $(H)$. These data were reviewed in the first stage, and initial analyses were performed on them. Then, these data were used for modeling into a set of basic SVR models to simulate their behavior to evaluate the FOS parameter. Different models were designed, and the best ones were selected according to performance and flexibility for different conditions. Among the various SVR models, the RBF model was developed with a lower error rate (RMSE $=0.076$ and MAE $=0.046)$ and higher accuracy $\left(R^{2}=0.947\right)$ in evaluating the FOS parameter. This basic model was used as a function by two optimization models WOA and HHO. Different optimization steps of the parameters of these two algorithms were performed to find different optimization conditions. Finally, both models came to close results with different conditions. The developed model was also successfully validated using new data with nine data samples. The results showed that combining a simulation model with optimization models can provide a new solution for the optimal design of important and sensitive projects. This research can be used as a new approach for FOS analysis.

Author Contributions: Conceptualization, W.W.; methodology, W.W. and J.Z.; software, W.W.; validation, W.W. and J.Z.; formal analysis, X.L. and W.W.; investigation, J.L. and L.L.; resources, Y.Z.; data curation, J.L.; writing—original draft preparation, W.W. and J.L.; writing-review and editing, X.L. and J.Z.; visualization, W.W. and J.Z.; supervision, X.L. and J.L.; project administration, J.L. and Y.Z.; funding acquisition, J.Z. All authors have read and agreed to the published version of the manuscript.

Funding: This study is supported by the Innovation—Driven Project of Central South University (2020CX040).

Institutional Review Board Statement: Not applicable.

Informed Consent Statement: Not applicable.

Data Availability Statement: All data generated or analysed during this study are included in this published article.

Conflicts of Interest: The authors confirm that this article content has no conflict of interest.

\section{References}

1. Zhou, J.; Li, E.; Yang, S.; Wang, M.; Shi, X.; Yao, S.; Mitri, H.S. Slope stability prediction for circular mode failure using gradient boosting machine approach based on an updated database of case histories. Saf. Sci. 2019, 118, 505-518. [CrossRef]

2. Tan, Ö. Investigation of soil parameters affecting the stability of homogeneous slopes using the Taguchi method. Eurasian Soil Sci. 2006, 39, 1248-1254. [CrossRef]

3. Erzin, Y.; Cetin, T. The prediction of the critical factor of safety of homogeneous finite slopes using neural networks and multiple regressions. Comput. Geosci. 2013, 51, 305-313. [CrossRef]

4. Nash, D. A comparative review of limit equilibrium methods of stability analysis. Slope Stab. 1987, 10008435061, 11-75.

5. Duncan, J.M. State of the Art: Limit Equilibrium and Finite-Element Analysis of Slopes. J. Geotech. Eng. 1996, 122, 577-596. [CrossRef]

6. Zucca, M.; Valente, M. On the limitations of decoupled approach for the seismic behaviour evaluation of shallow multi-propped underground structures embedded in granular soils. Eng. Struct. 2020, 211, 110497. [CrossRef]

7. Su, Z.; Shao, L. A three-dimensional slope stability analysis method based on finite element method stress analysis. Eng. Geol. 2021, 280, 105910. [CrossRef]

8. Liang, H.; Zhang, H. Identification of slope stability based on the contrast of BP neural network and SVM. In Proceedings of the 3rd International Conference on Computer Science and Information Technology, Chengdu, China, 9-11 July 2010; Volume 9, pp. 347-350.

9. Shahin, M.A.; Jaksa, M.B.; Maier, H.R. State of the art of artificial neural networks in geotechnical engineering. Electron. J. Geotech. Eng. 2008, 8, 1-26.

10. Zhou, J.; Li, C.; Arslan, C.A.; Hasanipanah, M.; Amnieh, H.B. Performance evaluation of hybrid FFA-ANFIS and GA-ANFIS models to predict particle size distribution of a muck-pile after blasting. Eng. Comput. 2021, 37, 265-274. [CrossRef] 
11. Mohamad, E.T.; Koopialipoor, M.; Murlidhar, B.R.; Rashiddel, A.; Hedayat, A.; Armaghani, D.J. A new hybrid method for predicting ripping production in different weathering zones through in situ tests. Measurement 2019, 147, 106826. [CrossRef]

12. Sun, L.; Koopialipoor, M.; Armaghani, D.J.; Tarinejad, R.; Tahir, M.M. Applying a meta-heuristic algorithm to predict and optimize compressive strength of concrete samples. Eng. Comput. 2019, 1-13. [CrossRef]

13. Armaghani, D.J.; Hatzigeorgiou, G.D.; Karamani, C.; Skentou, A.; Zoumpoulaki, I.; Asteris, P.G. Soft computing-based techniques for concrete beams shear strength. Procedia Struct. Integr. 2019, 17, 924-933. [CrossRef]

14. Asteris, P.G.; Apostolopoulou, M.; Skentou, A.D.; Moropoulou, A. Application of artificial neural networks for the prediction of the compressive strength of cement-based mortars. Comput. Concr. 2019, 24, 329-345.

15. Huang, L.; Asteris, P.G.; Koopialipoor, M.; Armaghani, D.J.; Tahir, M.M. Invasive Weed Optimization Technique-Based ANN to the Prediction of Rock Tensile Strength. Appl. Sci. 2019, 9, 5372. [CrossRef]

16. Zhou, J.; Chen, C.; Du, K.; Armaghani, D.J.; Li, C. A new hybrid model of information entropy and unascertained measurement with different membership functions for evaluating destressability in burst-prone underground mines. Eng. Comput. 2020, 1-19. [CrossRef]

17. Asteris, P.G.; Douvika, M.G.; Karamani, C.A.; Skentou, A.D.; Chlichlia, K.; Cavaleri, L.; Daras, T.; Armaghani, D.J.; Zaoutis, T.E. A Novel Heuristic Algorithm for the Modeling and Risk Assessment of the COVID-19 Pandemic Phenomenon. Comput. Model. Eng. Sci. 2020, 125, 815-828. [CrossRef]

18. Zhou, J.; Asteris, P.G.; Armaghani, D.J.; Pham, B.T. Prediction of ground vibration induced by blasting operations through the use of the Bayesian Network and random forest models. Soil Dyn. Earthq. Eng. 2020, 139, 106390. [CrossRef]

19. Apostolopoulou, M.; Asteris, P.G.; Armaghani, D.J.; Douvika, M.G.; Lourenço, P.B.; Cavaleri, L.; Bakolas, A.; Moropoulou, A. Mapping and holistic design of natural hydraulic lime mortars. Cem. Concr. Res. 2020, 136, 106167. [CrossRef]

20. Zhou, J.; Qiu, Y.; Armaghani, D.J.; Zhang, W.; Li, C.; Zhu, S.; Tarinejad, R. Predicting TBM penetration rate in hard rock condition: A comparative study among six XGB-based metaheuristic techniques. Geosci. Front. 2021, 12, 101091. [CrossRef]

21. Asteris, P.G.; Armaghani, D.J.; Hatzigeorgiou, G.D.; Karayannis, C.G.; Pilakoutas, K. Predicting the shear strength of reinforced concrete beams using artificial neural networks. Comput. Concr. 2019, 24, 469-488. [CrossRef]

22. Zhou, J.; Chen, C.; Armaghani, D.J.; Ma, S. Developing a hybrid model of information entropy and unascertained measurement theory for evaluation of the excavatability in rock mass. Eng. Comput. 2020, 1-24. [CrossRef]

23. Hajihassani, M.; Abdullah, S.S.; Asteris, P.G.; Armaghani, D.J. A Gene Expression Programming Model for Predicting Tunnel Convergence. Appl. Sci. 2019, 9, 4650. [CrossRef]

24. Guo, H.; Zhou, J.; Koopialipoor, M.; Armaghani, D.J.; Tahir, M.M. Deep neural network and whale optimization algorithm to assess flyrock induced by blasting. Eng. Comput. 2021, 37, 173-186. [CrossRef]

25. Armaghani, D.J.; Mohamad, E.T.; Narayanasamy, M.S.; Narita, N.; Yagiz, S. Development of hybrid intelligent models for predicting TBM penetration rate in hard rock condition. Tunn. Undergr. Space Technol. 2017, 63, 29-43. [CrossRef]

26. Zhou, J.; Li, X.; Mitri, H.S. Classification of Rockburst in Underground Projects: Comparison of Ten Supervised Learning Methods. J. Comput. Civ. Eng. 2016, 30, 04016003. [CrossRef]

27. Cavaleri, L.; Asteris, P.G.; Psyllaki, P.P.; Douvika, M.G.; Skentou, A.D.; Vaxevanidis, N.M. Prediction of Surface Treatment Effects on the Tribological Performance of Tool Steels Using Artificial Neural Networks. Appl. Sci. 2019, 9, 2788. [CrossRef]

28. Armaghani, D.J.; Momeni, E.; Asteris, P. Application of group method of data handling technique in assessing deformation of rock mass. Metaheuristic Comput. Appl. 2020, 1, 1-18.

29. Armaghani, D.J.; Koopialipoor, M.; Marto, A.; Yagiz, S. Application of several optimization techniques for estimating TBM advance rate in granitic rocks. J. Rock Mech. Geotech. Eng. 2019, 11, 779-789. [CrossRef]

30. Zhou, J.; Li, X.; Mitri, H.S. Evaluation method of rockburst: State-of-the-art literature review. Tunn. Undergr. Space Technol. 2018, 81, 632-659. [CrossRef]

31. Cavaleri, L.; Chatzarakis, G.E.; Di Trapani, F.; Douvika, M.G.; Roinos, K.; Vaxevanidis, N.M.; Asteris, P.G. Modeling of surface roughness in electro-discharge machining using artificial neural networks. Adv. Mater. Res. 2017, 6, 169-184.

32. Armaghani, D.J.; Asteris, P.G. A comparative study of ANN and ANFIS models for the prediction of cement-based mortar materials compressive strength. Neural Comput. Appl. 2020,1-32. [CrossRef]

33. Zhou, J.; Guo, H.; Koopialipoor, M.; Armaghani, D.J.; Tahir, M.M. Investigating the effective parameters on the risk levels of rockburst phenomena by developing a hybrid heuristic algorithm. Eng. Comput. 2020, 1-16. [CrossRef]

34. Yang, H.; Koopialipoor, M.; Armaghani, D.J.; Gordan, B.; Khorami, M.; Tahir, M.M. Intelligent design of retaining wall structures under dynamic conditions. Steel Compos. Struct. 2019, 31, 629-640.

35. Huang, J.; Koopialipoor, M.; Armaghani, D.J. A combination of fuzzy Delphi method and hybrid ANN-based systems to forecast ground vibration resulting from blasting. Sci. Rep. 2020, 10, 1-21. [CrossRef] [PubMed]

36. Lu, S.; Koopialipoor, M.; Asteris, P.G.; Bahri, M.; Armaghani, D.J. A Novel Feature Selection Approach Based on Tree Models for Evaluating the Punching Shear Capacity of Steel Fiber-Reinforced Concrete Flat Slabs. Materials 2020, 13, 3902. [CrossRef]

37. Pham, B.T.; Nguyen, M.D.; Nguyen-Thoi, T.; Ho, L.S.; Koopialipoor, M.; Quoc, N.K.; Armaghani, D.J.; Van Le, H. A novel approach for classification of soils based on laboratory tests using Adaboost, Tree and ANN modeling. Transp. Geotech. 2021, 27, 100508. [CrossRef]

38. Gao, J.; Koopialipoor, M.; Armaghani, D.J.; Ghabussi, A.; Baharom, S.; Morasaei, A.; Shariati, A.; Khorami, M.; Zhou, J. Evaluating the bond strength of FRP in concrete samples using machine learning methods. Smart Struct. Syst. 2020, 26, 403-418. [CrossRef] 
39. Koopialipoor, M.; Tootoonchi, H.; Armaghani, D.J.; Mohamad, E.T.; Hedayat, A. Application of deep neural networks in predicting the penetration rate of tunnel boring machines. Bull. Int. Assoc. Eng. Geol. 2019, 78, 6347-6360. [CrossRef]

40. Tang, D.; Gordan, B.; Koopialipoor, M.; Armaghani, D.J.; Tarinejad, R.; Pham, B.T.; Van Huynh, V. Seepage Analysis in Short Embankments Using Developing a Metaheuristic Method Based on Governing Equations. Appl. Sci. 2020, 10, 1761. [CrossRef]

41. Koopialipoor, M.; Armaghani, D.J.; Hedayat, A.; Marto, A.; Gordan, B. Applying various hybrid intelligent systems to evaluate and predict slope stability under static and dynamic conditions. Soft Comput. 2019, 23, 5913-5929. [CrossRef]

42. Verma, A.K.; Singh, T.N.; Chauhan, N.K.; Sarkar, K. A Hybrid FEM-ANN Approach for Slope Instability Prediction. J. Inst. Eng. Ser. A 2016, 97, 171-180. [CrossRef]

43. Rukhaiyar, S.; Alam, M.N.; Samadhiya, N.K. A PSO-ANN hybrid model for predicting factor of safety of slope. Int. J. Geotech. Eng. 2017, 3, 1-11. [CrossRef]

44. Chakraborty, A.; Goswami, D. Prediction of slope stability using multiple linear regression (MLR) and artificial neural network (ANN). Arab. J. Geosci. 2017, 10, 385. [CrossRef]

45. Samui, P. Slope stability analysis: A support vector machine approach. Environ. Earth Sci. 2008, 56, 255-267. [CrossRef]

46. Abdalla, J.; Attom, M.F.; Hawileh, R.A. Prediction of minimum factor of safety against slope failure in clayey soils using artificial neural network. Environ. Earth Sci. 2014, 73, 5463-5477. [CrossRef]

47. Khandelwal, M.; Rai, R.; Shrivastva, B.K. Evaluation of dump slope stability of a coal mine using artificial neural network. Geomech. Geophys. Geo Energy Geo Resour. 2015, 1, 69-77. [CrossRef]

48. Cortes, C.; Vapnik, V. Support vector machine. Mach. Learn. 1995, 20, 273-297. [CrossRef]

49. Li, E.; Zhou, J.; Shi, X.; Armaghani, D.J.; Yu, Z.; Chen, X.; Huang, P. Developing a hybrid model of salp swarm algorithm-based support vector machine to predict the strength of fiber-reinforced cemented paste backfill. Eng. Comput. 2020, 1-22. [CrossRef]

50. Zhou, J.; Qiu, Y.; Zhu, S.; Armaghani, D.J.; Li, C.; Nguyen, H.; Yagiz, S. Optimization of support vector machine through the use of metaheuristic algorithms in forecasting TBM advance rate. Eng. Appl. Artif. Intell. 2021, 97, 104015. [CrossRef]

51. Ghezelbash, R.; Maghsoudi, A.; Carranza, E.J.M. Performance evaluation of RBF- and SVM-based machine learning algorithms for predictive mineral prospectivity modeling: Integration of S-A multifractal model and mineralization controls. Earth Sci. Inform. 2019, 12, 277-293. [CrossRef]

52. Yu, Z.; Shi, X.; Zhou, J.; Rao, D.; Chen, X.; Dong, W.; Miao, X.; Ipangelwa, T. Feasibility of the indirect determination of blast-induced rock movement based on three new hybrid intelligent models. Eng. Comput. 2019, 1-16. [CrossRef]

53. Shi, X.-Z.; Zhou, J.; Wu, B.-B.; Huang, D.; Wei, W. Support vector machines approach to mean particle size of rock fragmentation due to bench blasting prediction. Trans. Nonferrous Met. Soc. China 2012, 22, 432-441. [CrossRef]

54. Armaghani, D.J.; Koopialipoor, M.; Bahri, M.; Hasanipanah, M.; Tahir, M.M. A SVR-GWO technique to minimize flyrock distance resulting from blasting. Bull. Int. Assoc. Eng. Geol. 2020, 1-17. [CrossRef]

55. Zhou, J.; Li, X.; Shi, X. Long-term prediction model of rockburst in underground openings using heuristic algorithms and support vector machines. Saf. Sci. 2012, 50, 629-644. [CrossRef]

56. $\mathrm{Wu}, \mathrm{H} .-\mathrm{C}$. The Karush-Kuhn-Tucker optimality conditions in an optimization problem with interval-valued objective function. Eur. J. Oper. Res. 2007, 176, 46-59. [CrossRef]

57. Mirjalili, S.; Lewis, A. The Whale Optimization Algorithm. Adv. Eng. Softw. 2016, 95, 51-67. [CrossRef]

58. Aljarah, I.; Faris, H.; Mirjalili, S. Optimizing connection weights in neural networks using the whale optimization algorithm. Soft Comput. 2018, 22, 1-15. [CrossRef]

59. Yu, Z.; Shi, X.; Zhou, J.; Chen, X.; Qiu, X. Effective Assessment of Blast-Induced Ground Vibration Using an Optimized Random Forest Model Based on a Harris Hawks Optimization Algorithm. Appl. Sci. 2020, 10, 1403. [CrossRef]

60. Heidari, A.A.; Mirjalili, S.; Faris, H.; Aljarah, I.; Mafarja, M.; Chen, H. Harris hawks optimization: Algorithm and applications. Futur. Gener. Comput. Syst. 2019, 97, 849-872. [CrossRef]

61. Bao, X.; Jia, H.; Lang, C. A Novel Hybrid Harris Hawks Optimization for Color Image Multilevel Thresholding Segmentation. IEEE Access 2019, 7, 76529-76546. [CrossRef]

62. Du, P.; Wang, J.; Hao, Y.; Niu, T.; Yang, W. A novel hybrid model based on multi-objective Harris hawks optimization algorithm for daily PM2.5 and PM10 forecasting. Appl. Soft Comput. 2020, 96, 106620. [CrossRef]

63. Zhou, J.; Koopialipoor, M.; Li, E.; Armaghani, D.J. Prediction of rockburst risk in underground projects developing a neuro-bee intelligent system. Bull. Eng. Geol. Environ. 2020, 79, 1-15. [CrossRef]

64. Bai, C.; Nguyen, H.; Asteris, P.G.; Nguyen-Thoi, T.; Zhou, J. A refreshing view of soft computing models for predicting the deflection of reinforced concrete beams. Appl. Soft Comput. 2020, 97, 106831. [CrossRef]

65. Zhou, J.; Qiu, Y.; Zhu, S.; Armaghani, D.J.; Khandelwal, M.; Mohamad, E.T. Estimation of the TBM advance rate under hard rock conditions using XGBoost and Bayesian optimization. Undergr. Space 2020, in press. [CrossRef]

66. Xu, H.; Zhou, J.; Asteris, P.G.; Armaghani, D.J.; Tahir, M.M. Supervised Machine Learning Techniques to the Prediction of Tunnel Boring Machine Penetration Rate. Appl. Sci. 2019, 9, 3715. [CrossRef]

67. Li, C.; Zhou, J.; Armaghani, D.J.; Li, X. Stability analysis of underground mine hard rock pillars via combination of finite difference methods, neural networks, and Monte Carlo simulation techniques. Undergr. Space 2020. [CrossRef]

68. Zhou, J.; Li, E.; Wei, H.; Li, C.; Qiao, Q.; Armaghani, D.J. Random Forests and Cubist Algorithms for Predicting Shear Strengths of Rockfill Materials. Appl. Sci. 2019, 9, 1621. [CrossRef] 
69. Zhang, H.; Zhou, J.; Armaghani, D.J.; Tahir, M.M.; Pham, B.T.; Van Huynh, V. A Combination of Feature Selection and Random Forest Techniques to Solve a Problem Related to Blast-Induced Ground Vibration. Appl. Sci. 2020, 10, 869. [CrossRef]

70. Fang, Q.; Nguyen, H.; Bui, X.-N.; Nguyen-Thoi, T.; Zhou, J. Modeling of rock fragmentation by firefly optimization algorithm and boosted generalized additive model. Neural Comput. Appl. 2020,1-17. [CrossRef]

71. Zhou, J.; Shi, X.; Du, K.; Qiu, X.; Li, X.; Mitri, H.S. Feasibility of random-forest approach for prediction of ground settlements induced by the construction of a shield-driven tunnel. Int. J. Geomech. 2017, 17, 04016129. [CrossRef]

72. Wang, H.; Xu, W.; Xu, R. Slope stability evaluation using Back Propagation Neural Networks. Eng. Geol. 2005, 80, 302-315. [CrossRef]

73. Zhou, K.-P.; Chen, Z.-Q. Stability Prediction of Tailing Dam Slope Based on Neural Network Pattern Recognition. In Proceedings of the 2nd International Conference on Environmental and Computer Science, Dubai, United Arab Emirates, 28-30 December 2009; pp. 380-383.

74. Sakellariou, M.G.; Ferentinou, M.D. A study of slope stability prediction using neural networks. Geotech. Geol. Eng. 2005, 23, 419-445. [CrossRef]

75. Xu, W.; Xie, S.; Jean-Pascal, D.; Nicolas, B.; Imbert, P. Slope stability analysis and evaluation with probabilistic artificial neural network method. Site Investig. Sci. Technol. 1999, 3, 19-21.

76. Sah, N.; Sheorey, P.; Upadhyaya, L. Maximum likelihood estimation of slope stability. Int. J. Rock Mech. Min. Sci. Geomech. Abstr. 1994, 31, 47-53. [CrossRef] 